\title{
4. EL DERECHO DE AUTODETERMINACIÓN EN NUESTRA RECIENTE VIDA CONSTITUCIONAL: ANÁLISIS Y PROBLEMÁTICA
}

ROBERTO VICIANO PASTOR

Profesor Titular (interino) de Derecho Constitucional Universidad de Valencia 


\section{SUMARIO}

1. CONCEPTO Y SUJETOS DEL DERECHO A LA AUTODETERMINACION.II. LA AUTODETERMINACIÓN EN EL MOMENTO CONSTITUYENTE.-a) La redacción del artículo 1.2 de la Constitución. b) La autodeterminación y el artículo 2 de la Constitución. c) El intento de incorporación a la Constitución del procedimiento de autodeterminación. d) Constitución y autodeterminación. III. LA RECIENTE REIVINDICACION DEL DERECHO A LA AUTODETERMINACION EN ESPANA.-a) La proposición no de ley del Parlamento de Cataluña. b) La proposición no de ley del Parlamento Vasco. c) Valoración global de las resoluciones autodeterministas aprobadas por los Parlamentos Vasco y de Cataluña. IV. ANALISIS DE LAS RAZONES QUE LLEVARON AL REPLANTEAMIENTO DEL DERECHO DE AUTODETERMINACION.-V. ANALISIS JURIDICO DE LOS acuerdos de los Parlamentos de Cataluña Y EUSKadi.-VI. ANALISIS POLITICO DEL CONTENIDO DE LOS ACUERDOS DE LOS PARLAMENTOS DE CATALUÑA Y EUSKADI.-a) ¿Tiene sentido reconocer el derecho de autodeterminación en un Estado democrático que goza de un sistema de descentralización política? b) La sombra de la desconfianza politica. c) Un grave riesgo politico. 
Revista de Derecho Político, núm. 34, 1991, pp. 143-188

\title{
4. EL DERECHO DE AUTODETERMINACIÓN EN NUESTRA RECIENTE VIDA CONSTITUCIONAL: ANÁLISIS Y PROBLEMÁTICA
}

\author{
POR \\ ROBERTO VICIANO PASTOR \\ Profesor Titular (interino) de Derecho Constitucional \\ Universidad de Valencia
}

No cabe duda alguna de que el derecho de autodeterminación ${ }^{1}$ fue el protagonista del debate político y jurídico-constitucional en España alrededor de los primeros meses de la década de los noventa. Desde el 12 de diciembre de 1989, en que la Comisión de Organización y Administración de la Generalidad y Gobierno Local del Parlamento de Cataluña adoptó la Resolución 98/III sobre el derecho de autodeterminación de la nación catalana $^{2}$, hasta que el 15 de febrero de 1990 el Pleno del Parlamento Vasco aprobó la proposición no de ley sobre el derecho de autodeterminación del pueblo vasco ${ }^{3}$, e incluso semanas después de este último hecho, pudimos asistir a través de los medios de comunicación social a un fuerte enfren-

1 Le denominamos «derecho» puesto que se encuentra positivizado en el artículo $1 .^{\circ}$ del Pacto Internacional de Derechos Civiles y Políticos y del Pacto Internacional de Derechos Económicos, Sociales y Culturales (Nueva York, 16 de diciembre de 1966), firmados y ratificados por España y publicados en el BOE núm. 103, de 30 de abril de 1977, con lo cual, en aplicación del artículo 96.1 de la Constitución, forman parte del ordenamiento jurídico español. Otra cuestión será la interpretación que se ha dado o se pueda dar al tenor literal del precepto, de lo que nos ocuparemos más adelante. Sobre esta problemática en general, sin ceñirse a un determinado pais, vid. Jean F. GuILHAUDIS, "Le droit positif à l'autodétermination", en Le droit à l'autodétermination, Presses d'Europe, Niza 1980, pp. 11-39.

${ }^{2}$ Butlletí del Parlament de Catalunya, núm. 120, de 18 de diciembre de 1989, p. 7791 .

3 Boletin Oficial del Parlamento Vasco, III Legislatura, núm. B-IV-134-135 (d) alea, de 26 de febrero de 1990. 
tamiento dialéctico en el plano político y una avalancha de opiniones de reconocidos iuspublicistas y politólogos.

Sin embargo, no es la primera vez que el derecho de autodeterminación ha sido objeto de debate en nuestra reciente historia constitucional. Ya en la discusión constituyente surgió directa o indirectamente en varias ocasiones como tendremos oportunidad de recordar. Por ello, en este trabajo nos proponemos estudiar si estos acuerdos han supuesto alguna alteración de las posturas de las fuerzas nacionalistas en el debate constituyente, cuáles han sido las razones de que se hayan aprobado y los problemas juridicos y políticos que han podido surgir o han sido planteados por la doctrina. Pero antes de adentrarnos en estos análisis, debemos recordar algunas notas sobre el concepto y sujetos del derecho de autodeterminación.

I. . CONCEPTO Y SUJETOS DEL DERECHO A LA AUTODETERMINACIÓN

Aunque algunos autores buscan antecedentes del derecho de autodeterminación en la Revolución americana ${ }^{4}$ o en la Revolución francesa $^{5}$, la mayoria de la doctrina señala como el precedente más claro el principio de las nacionalidades que formulara Mancini, según el cual toda nación tiende a constituirse en Estado ${ }^{6}$. Esta idea política fue actualizada por el presidente norteamericano Wilson cuando defendió el principio de

4 Solé Tura defiende que la Declaración de Independencia de los Estados Unidos de América de 4 de julio de 1776 es el primer ejemplo del principio de autodeterminación (J. SOLÉ TURA: Nacionalidades y nacionalismos en España. Autonomias, federalismo, autodeterminación, Alianza Editorial, Madrid 1985, pp. 141142).

5 GuRUTZ JÁUREGUI: «El derecho de autodeterminación en las sociedades desarrolladas", en Autodeterminación de los pueblos. Un reto para Euskadi y Europa, Herria 2000 Eliza, Bilbao 1985, t. I, pp. 157-158.

6 La enunciación de dicho principio puede consultarse en P. S. MANCINI: «De la nacionalidad como fundamento del Derecho de Gentes», en Sobre la nacionalidad, Tecnos, Madrid 1985, pp. 3-65. 
autodeterminación de los pueblos como uno de los ejes en los que se debían basar las relaciones internacionales en el periodo de entreguerras ${ }^{7}$.

Sin embargo, el tránsito desde la utilización retórica hasta la positivación del derecho de autodeterminación se alargó enormemente. Fue recogido, como principio, en los artículos 1 y 55 de la Carta de las Naciones Unidas ${ }^{8}$ pero se rechazó su inclusión, a pesar de ser explícitamente solicitado por algunos paises ${ }^{9}$, en la Declaración Universal de Derechos Humanos ${ }^{10}$. Finalmente, lo recogieron los Pactos de Derechos Humanos de 1966 en sus respectivos artículos $1 .^{\circ}$ con idéntica redacción ${ }^{11}$.

Por todo ello, como ha explicado magistralmente GROS ESPIELL, «la tesis de que la libre determinación era un principio, pero no un derecho, es decir, que no atribuia a ningún sujeto de derecho un poder juridico a exigir su reconocimiento y efectividad, fue sostenida por la mayoría de la doctrina del Derecho Internacional en la década de los cuarenta y todavia, por algunos autores en los años cincuenta. Incluso en los primeros años de vigencia de la Carta (de las Naciones Unidas) algunas potencias colonialistas llegaron a sostener que era un principio de carácter moral o político, pero no un principio de Derecho Internacional. Pero estas posiciones

7 WiLson formuló el principio en su famoso discurso de 12 de febrero de 1918 cuando entre otras cosas, afirmó: «Esta guerra tiene su origen en el menosprecio de los derechos de las pequeñas naciones y de las nacionalidades carentes de unidad y de las fuerza necesaria para hacer triunfar sus aspiraciones a determinar su propia soberanía y sus propias formas de vida política. La autodeterminación no debe ser, en adelante, una fórmula vacia. Es un principio imperioso, de acción, que los hombres no ignorarán ya más que a costa de sus riesgos y peligros». (cit. en J. R. RECALDE: "El derecho de autodeterminación", en Cuadernos de Alzate, núm. 10, 1988, p. 32). Sobre la problemática del derecho de autodeterminación en el periodo de entreguerras, vid. A. CoBban: National Self-Determination, Oxford University Press, Londres 1945.

\& Artículo 1. «Los propósitos de las Naciones Unidas son: ... 2. Fomentar entre las naciones relaciones de amistad basadas en el respeto al principio de la igualdad de derechos y al de la libre determinación de los pueblos, y tomar otras medidas adecuadas para fortalecer la paz universal...".

Artículo 55. «Con el propósito de crear las condiciones de estabilidad y bienestar necesarias para las relaciones pacificas y amistosas entre las naciones, basadas en el respeto al principio de la igualdad de derechos y al de la libre determinación de los pueblos, la Organización promoverá: ...".

9 J. A. de OBIETA: El derecho humano de la autodeterminación de los pueblos, Tecnos, Madrid 1989, p. 58

10 ONU, Asamblea General, Resol. 217 A (III), de 20 de diciembre de 1948.

11 «Todos los pueblos tienen el derecho de libre determinación. En virtud de este derecho establecen libremente su condición política y proveen asimismo a su desarrollo económico, social y cultural” [Artículo $1 .^{\circ}$ del Pacto Internacional de Derechos Civiles y Políticos y del Pacto Internacional de Derechos Económicos, Sociales y Culturales (ONU, Asamblea General, Resol. 2200 A (XXI), de 16 de diciembre de 1966)]. 
sólo tiene hoy un valor histórico, ya que son obviamente insostenibles frente a los textos internacionales positivos actualmente existentes..." ${ }^{12}$. Como ha señalado TRUYOL SERRA, los Pactos Internacionales de 1966 son auténticos convenios, presentados a la firma y ratificación de los Estados, que han entrado en vigor al depositarse el trigésimo quinto instrumento de ratificación ${ }^{13}$.

La genérica definición del derecho de autodeterminación que nos ofrecen los artículos $1 .^{\circ}$ de los citados Pactos, la podemos completar con la que ha formulado el profesor CAVERO. Para él, dicho derecho, en su aspecto politico, consiste en «la capacidad reconocida, o exigida, por un pueblo para decidir integrarse o mantenerse dentro de un Estado plurinacional, regional o federal, o bien para independizarse constituyendo un nuevo Estado y, conseguida esa situación, confederarse o no, todo ello basado en el reconocimiento de una soberania originaria o en unas condiciones acumuladas, de tal entidad, que justifiquen la adquisición de este derechom ${ }^{14}$.

Sin embargo, si la definición y contenido no plantea grandes divergencias en la doctrina, no puede decirse lo mismo sobre la concreción del sujeto del derecho de autodeterminación, es decir, sobre qué debemos entender por pueblo ${ }^{15}$.

Este extremo ha sido el origen de diversas confusiones doctrinales. En relación con los derechos humanos hay que diferenciar quiénes son los sujetos del derecho, en abstracto, de los supuestos en los que los sujetos están legitimados para ejercer el derecho. No hay que olvidar que todo derecho tiene limites en su ejercicio. Consiguientemente, el derecho de autodeterminación lo pueden tener todos los pueblos pero no todos pueden estar legitimados para ejercerlo.

12 H. Gros ESPIELL: «El derecho a la libre determinación de los pueblos y los derechos humanos», en Anuario de Derechos Humanos, núm. 1, 1981, pp. 140-141.

13 A. Truyol Serra: Los derechos humanos, Tecnos, Madrid 1979, p. 32 . A este respecto Obieta nos remarca que «son verdaderas convenciones o tratados internacionales obligatorios para los Estados que los han ratificado» (J. A. DE OBIETA: El derecho humano de la autodeterminación de los pueblos, Tecnos, Madrid, 1989, p. 59.

I. Cavero: «La Constitución ante la autodeterminación», en Revista de la Facultad de Derecho de la Universidad Complutense, núm. 15, 1989, p. 321.

${ }_{15}$ La dificultad del empeño se pone de relieve con las conclusiones de Ruiloba, para quien «no existe la posibilidad de una definición cualitativa del concepto pueblo, y en cada caso habría que plantearse el problema de qué grado de diferenciación resulta suficiente para que el pueblo en cuestión pueda gozar del derecho a la autodeterminaçión y eventualmente acceder a la independencia" $(E$. RuILoBa SANTANA: «Una nueva categoría en el panorama de la subjetividad internacional: el concepto de pueblo", en Estudios de Derecho Internacional. Homenaje al profesor Miaja de la Muela, Tecnos, Madrid 1978, t. I, p. 325). 
Planteamos todo esto porque por importantes sectores doctrinales e incluso en la práctica de las Naciones Unidas se ha identificado el sujeto en abstracto con los sujetos legitimados para ejercerlo. En nuestra opinión, se ha producido tal confusión porque se ha entendido que si determinados sujetos no iban a estar legitimados para ejercerlo, era mejor, para evitar problemas y falsas expectativas, empezar por no atribuirles el derecho.

Asi, un importante sector doctrinal defiende que el término «pueblo» hace referencia exclusivamente a la población de un Estado constituido o los pueblos colonizados ${ }^{16}$, y en último extremo, a los pueblos no coloniales bajo régimen no democrático o que sufren cualquier tipo de discriminación en el Estado del que forman parte ${ }^{17}$ o que son objeto de dominación armada extranjera ${ }^{18}$. Como puede deducirse, esta postura basada en las resoluciones adoptadas por Naciones Unidas, no plantea una definición del vocablo «pueblo» sino un catálogo de los pueblos que se entiende tienen legitimación para ejercitar el derecho de autodeterminación.

Esta confusión parece lógica proviniendo de un foro de Estados en donde es más lógico limitar que potenciar el alcance de un derecho que es peligroso para la supervivencia de los miembros que lo componen. El problema ha surgido porque, al ser incluido en los textos que lo han positivizado, el derecho de autodeterminación tuvo que ser atribuido, como

16 Esta interpretación se fundamenta en la «Declaración sobre la Concesión de la Independencia a los Países y Pueblos Coloniales" [ONU, Asamblea General, Resol. 1514 (XV), del 14 de diciembre de 1960], que limitaba en su sexto punto la proclamación del derecho a la libre determinación de todos los pueblos señalando que utodo intento encaminado a quebrantar total o parcialmente la unidad nacional y la integridad territorial de un país es incompatible con los propósitos y principios de la Carta de las Naciones Unidas» (H. GRos ESPIELL: «El derecho a la libre determinación de los pueblos y los derechos humanos", en Anuario de Derechos Humanos, núm. 1981, pp. 143-144. La totalidad de este artículo es un buen ejemplo de la interpretación tradicional y restrictiva del derecho de autodeterminación).

17. Esta última interpretación tendría su fundamento en la «Declaración sobre los Principios de Derecho Internacional referentes a las Relaciones de Amistad y a la Cooperación entre los Estados de conformidad con la Carta de las Naciones Unidas" [ONU, Asamblea General, Resol. 2625 (XXV), del 24 de octubre de 1970] que al negar su amparo al derecho de autodeterminación cuando suponga la violación de la integridad territorial de algún Estado, entiende que dichos Estados deben conducirse "de conformidad con el principio de la igualdad de derechos y de la libre determinación de los pueblos antes descritos y estén, por tanto, dotados de un gobierno que represente a la totalidad del pueblo perteneciente al territorio, sin distinción por motivos de raza, credo o color" (A. REMiro Brotons: Derecho Internacional Público. I. Principios fundamentales. Tecnos, Madrid 1981, p. 173).

18 Remiro Brotons señala que frente a las invasiones armadas de Kampuchea y Afganistán, la Asamblea de las Naciones Unidas solicitó la retirada de las tropas extranjeras y el respeto a la libre determinación de los pueblos ocupados, convirtiéndolos en sujetos del derecho a la autodeterminación (Derecho Internacional Público. I. Principios fundamentales, Tecnos, Madrid 1981, pp. 168-169). 
todo derecho humano, a todo el género humano. Pero, como ya hemos reseñado, tanto antes como después de su positivización, los Estados ya constituidos han intentado, al referirse a este derecho, limitar su ámbito de actuación. En este sentido, también los nuevos Estados surgidos de la descolonización se han sumado al intento limitador de los sujetos de la libre determinación pues normalmente son amalgamas de pueblos diferenciados cuando no enfrentados, integrados en un solo Estado por la exclusiva voluntad de la potencia colonizadora ${ }^{19}$.

Pero frente al interés de los Estados, topamos con la rotundidad de la redacción de los artículos $1 .^{\circ}$ de los Pactos Internacionales los cuales prescriben que el sujeto del derecho de libre determinación son todos los pueblos. Parece evidente que si se hubiera deseado limitar este derecho sólo a algunos pueblos se habría especificado, tal como se ha hecho en otras ocasiones ${ }^{20}$. Esta colisión entre el tenor literal y las interpretaciones de la Asamblea General de las Naciones Unidas ha llevado a OBIETÁ a recordar que "la Asamblea General no es un Parlamento mundial capaz de promulgar leyes obligatorias para los Estados. Es solamente un órgano político cuyo único fin es promover el mantenimiento de la paz y la cooperación entre los Estados, para lo que dispone de determinados poderes de recomendación que nunca son obligatorios» ${ }^{21}$.

Por el contrario, los Pactos, una vez entran en vigor como consecuencia de la ratificación por más de treinta y cinco Estados, tienen vida jurídica independiente de los órganos que los crearon y «si surgiere alguna duda en la interpretación de sus cláusulas no sería la Asamblea General la llamada a dirimirla sino los mismos Estados parte y, en último término, el Tribunal Internacional de Justicia» ${ }^{22}$.

Por tanto, la interpretación, si se quiere interesada, dada por la Asamblea General de las Naciones Unidas sobre el sujeto del derecho de autodeterminación debe ser rechazada de plano y la discusión doctrinal sobre este aspecto debe centrarse en dar un contenido al término «pueblo», aspecto en el que tampoco existe unanimidad en la doctrina.

19 Jean F. GUILHAUDIS: “Le droit positif à l'autodétermination", en Le droit à l'autodétermination, Institut Européen des Hautes Études Internationales, Niza 1980, p. 24.

20 Guy HéRAuD: «Modèle pour une application générale du droit d'autodérmination", en Le droit à l'autodérmination, Presses d'Europe, Niza 1980, p. 42.

21 J. A. DE OBIETA: El derecho humano de la autodeterminación de los pueblos, Tecnos, Madrid 1989, pp. 56-57.

${ }_{22}$ José A. DE OBIETA, op. cit., p. 59. 
Para un importante sector, pueblo es toda colectividad que posee las caracteristicas objetivas y subjetivas que se atribuyen a la nación ${ }^{23}$. En definitiva, estos autores identifican pueblo con nación. Pero dado que el término nación no puede acotarse técnicamente se ha recurrido al concepto de etnia que parece que sí puede ser definido con criterios científicos. Este concepto vendría a englobar los elementos objetivos del concepto nación. Consecuentemente, pueblo sólo sería aquel conjunto de ciudadanos que objetivamente forman una etnia y, además, tengan conciencia de tal ${ }^{24}$.

Sin embargo, a pesar de su apariencia científica, y como bien ha puesto de relieve entre nosotros RECALDE, dicha solución plantea dos objeciones ${ }^{25}$.

- El concepto de etnia es muy ambiguo.

- Existen innumerables colectivos que se sienten pueblos diferenciados y sin embargo pertenecen a la misma etnia ${ }^{26}$.

Consecuentemente, puesto que a pesar de buscar elementos objetivos que asienten el concepto de pueblo seguimos en la ambigüedad, debemos de concluir con HÉRAUD que «desde la perspectiva de la democracia, un pueblo se define subjetivamente; un pueblo es toda colectividad que quiera conferirse el carácter de pueblo" ${ }^{27}$. Dado que el derecho de autodeterminación ha sido definido como una consecuencia directa del principio democrático ${ }^{28}$, parece que ningún criterio de delimitación de su sujeto po-

${ }^{23}$ Ruiloba nos pone de manifiesto que para determinar el concepto de pueblo «es preciso partir del concepto de «nación», al que, sin desplazar del todo, en alguna medida reemplaza hoy el concepto de pueblo", ya que tiene un cariz más democrático (E. RuILOBA SANTANA: «Una nueva categoría en el panorama de la subjetividad internacional»: el concepto de pueblon, en Estudios de Derecho Internacional. Homenaje al profesor Miaja de la Muela, Tecnos, Madrid 1978, t. I, pp. 305 y 314.

24 Por todos, José A. DE OBIETA: El derecho humano de la autodeterminación de los pueblos, Tecnos, Madrid 1989, pp. 37-46.

${ }_{25}$ José R. RECALDE: «El derecho de autodeterminación», en Autodeterminación de los pueblos. Un reto para Euskadi y Europa, Herria 2000 Eliza, Bilbao 1985, t. I, pp. 203-204.

26 Este argumento también ha sido puesto de relieve por Guy HÉraUD: “Democracia y autodeterminación», en Autodeterminación de los pueblos..., t. I, p. 60.

${ }^{27}$ Guy Héraud, op cit., t. I, p. 62. Esta postura ha sido criticada desde algunas posiciones doctrinales, pues señalan dichos autores que dicha postura puede conducir al absurdo de que se considere "pueblo" a la población de un municipio y por una aplicación generosa del derecho de autodeterminación se fragmente en exceso la comunidad internacional. A. DE BLAS ha defendido que cel derecho de 
dría ser mejor que la propia voluntad y conciencia de ser pueblo que tenga cualquier comunidad humana ${ }^{29}$. Evidentemente, en última instancia, el sentirse parte de un colectivo es una decisión sentimental, psicológica.

Es cierto que los integrantes de un pueblo fundamentan su unión en elementos objetivos. Pero la elección de ese factor objetivo, despreciando otros que podrian haber conducido a soluciones diferentes, presupone una previa voluntad, una tendencia psicológica, primaria, que busca en el dato objetivo una explicación y una justificación racional de ese sentimiento previo ${ }^{30}$. De poco sirve que desde fuera del colectivo se ponga de relieve

autodeterminación pretende salvar el componente antidemocrático que amenaza al principio de las nacionalidades, pero lo hace al precio de asumir un principio que puede conducir al absurdo de levantar una organización estatal allí donde coincida la voluntad o el capricho de un colectivo indeterminado de personas" («Sobre el derecho de autodeterminación”, en Cuadernos de Alzate, núm. 10, 1988, p. 9). En el fondo estas posiciones to único que ponen de relieve es una profunda desconfianza en los principios democráticos y en el sentido común de los ciudadanos.

${ }^{28}$ Para Solé Tura ues indudable que el derecho de autodeterminación de los pueblos es un principio democrático esencial que debe ser defendido a ultranza en su significación exacta. El derecho de autodeterminación quiere decir derecho a la libertad y a la independencia de los pueblos frente a las grandes potencias que intentan controlar el mundo en función de sus intereses" (J. SoLÉ TURA: Nacionalidades y nacionalismos en España. Autonomías, federalismo y autodeterminación, Alianza Editorial, Madrid 1985, p. 146). No entendemos bien por qué el autor no sigue con dicho discurso lógico y reconoce que, además de lo que plantea, las medianas y pequeñas potencias pueden intentar controlar a pueblos que habiten en su interior en función de sus intereses globales, en función de la llamada «razón de Estado".

En un sentido más globalista, Obieta ha señalado la relación entre derecho de autodeterminación y principio democrático poniendo de relieve que utoda comunidad natural, formada por personas humanas y libres, posee en si, en virtud de su propia naturaleza, el poder de gobernarse a si misma, sin injerencias exteriores de ninguna clase, para obtener los fines que le son especificos. Tal comunidad determina, por consiguiente, libremente la forma como va a gobernarse en el futuro de acuerdo con sus tradiciones y los deseos expresados por su población $y$, al obrar asi y en la medida en que obre asi, ejercerá su derecho de autodeterminación" (José A. DE OBIETA: El derecho humano de la autodeterminación de los pueblos, Tecnos, Madrid 1989, p. 31).

${ }_{29}$ En este sentido, Ruiloba nos recuerda que un sector de la doctrina, encabezado por Delbez, entiende que "serian naciones aquellas comunidades diferenciadas por factores étnicos, lingüísticos, culturales, religiosos, etc., mientras que para ser pueblos bastaría la voluntad colectiva manifestada a través del ejercicio del derecho de libre determinación» (E. RuILOBA SANTANA: «Una nueva categoria en el panorama de la subjetividad internacional: el concepto de pueblo", en Estudios de Derecho Internacional..., t. I, p. 312).

${ }^{30}$ Como ha matizado Ruiloba, frente al carácter contingente o accidental que tienen los elementos objetivos, pues unas veces son unos y otras se utilizan otros, la voluntad colectiva de vivir como pueblo o sentirse pueblo es imprescin- 
la debilidad de los elementos objetivos o la presencia de elementos que identifican a ese colectivo con otro colectivo humano. Lo importante será la visión que tengan sus integrantes de esos factores objetivos.

Puesto que hemos concluido que dicho derecho debe ser predicable de todos los pueblos, y que, al utilizar este concepto, no debemos referirnos sólo a un grupo étnico que posea conciencia de tal, sino también a cualquier colectivo que se defina como pueblo, parece claro que, en España, no sólo los vascos, los gallegos o los catalanes, pueden ser considerados pueblos sino también los valencianos, los castellanos, los andaluces o los extremeños, por citar sólo algunos ejemplos. $Y$ consecuentemente todos ellos pueden ser, en abstracto, sujetos del derecho de autodeterminación. Pero es que, indudablemente también, es posible que, a pesar de que dichos colectivos humanos se sientan diferenciados respecto de sus vecinos, hayan logrado superar esas diferencias, tomando como referencia las similitudes e identidades comunes que existan entre ellos, y puedan conformar un único pueblo que sea sujeto del derecho de autodeterminación.

Analizado escuetamente el concepto y el sujeto del derecho de autodeterminación, podemos pasar a estudiar los intentos de constitucionalización del mismo a lo largo de los debates constituyentes.

\section{LA AUTODETERMINACIÓN EN EL MOMENTO CONSTITUYENTE}

En el momento de elaboración de la Constitución española de 1978, el derecho de autodeterminación se entendía predicable de los pueblos que componen España, no sólo por la extrema izquierda y los grupos nacionalistas, sino también por el Partido Socialista Obrero Español (PSOE) y por el Partido Comunista de España (PCE) e, incluso, por sectores de la Democracia Cristiana. En este sentido, cuando en las Cortes constituyentes se produjo el debate sobre la constitucionalización o no de este derecho, el diputado señor Letamendía recordó que el XX Congreso de los demócrata-cristianos europeos propugnaba el derecho de autodeterminación

dible. A pesar de ello, el autor entiende que también es necesaria una base objetiva (E. RuILOBa SANTANA: «Una nueva categoría en el panorama de la subjetividad internacional: el concepto de pueblo", en Estudios de Derecho Internacional..., t. I, p. 315). 
para todos los pueblos, incluido el alemán, y que dirigentes del PSOE habian participado en una manifestación pro autodeterminación en el País Vasco hacía sólo dos meses ${ }^{31}$. Además, los representantes del PSOE y del $P C E$ tuvieron que reconocer que, aunque rechazaban su constitucionalización, dicho derecho estaba recogido en las conclusiones del XXVII Congreso del PSOE y en el programa político del PCE ${ }^{32}$.

La autodeterminación se planteó en tres momentos de la discusión del texto de la Constitución ${ }^{33}$. En el primero de ellos, de manera indirecta, al tratar el tema de la soberanía (art. 1.2 del Proyecto de Constitución), pues sin que se reconocieran diversas soberanías o una cosoberanía en el Estado español no podía plantearse el derecho de autodeterminación. En los otros dos momentos se intentó constitucionalizar tal derecho incorporándolo al artículo 2 del Anteproyecto de Constitución y proponiendo un Título VIII bis que regulara el ejercicio de dicho derecho.

Vamos a analizarlos por orden de situación en la Carta Magna y, consecuentemente, por orden de discusión en el momento constituyente, centrándonos principalmente, para evitar reiteración de posiciones y argumentaciones, en los debates del Congreso de los Diputados.

\section{a) La redacción del artículo 1.2 de la Constitución}

El articulo 1.2 del Anteproyecto de Constitución presentado por la Ponencia: «Los poderes de todos los órganos del Estado emanan del pueblo

31 Diario de Sesiones del Congreso de los Diputados, Comisión Constitucional, núm. 91, 16 de junio de 1978, p. 3427.

${ }_{32}$ D.S.C.D., Comisión Constitucional, núm. 91, 16 de junio 1978, pp. 3429-30.

33 Dejamos a un lado la enmienda número 1094 (Constitución Española. Trabajos Parlamentarios, Cortes Generales, Madrid 1980, t. III, p. 2950) que presentó el senador vasco, señor Monreal Zia, al artículo 1.1 del Proyecto de Constitución remitido por el Congreso de los Diputados, proponiendo adicionar el siguiente texto: «La Constitución acepta el principio de que la ordenación presente y futura del Estado se sujetará a lo previsto en los artículos 1 y 55 de la Carta de las Naciones Unidas y al artículo $1 .^{\circ}$ del Pacto de Derechos Civiles de 1966». La razón estriba en que fue rechazada abrumadoramente en Comisión (Diario de Sesiones del Senado, Comisión de Constitución, núm. 39, 18 de agosto de 1978, p. 1576) y Pleno (D.S.S., Pleno, núm. 58,25 de septiembre de 1978, p. 2891), sin que se suscitara prácticamente debate.

Igualmente, no estudiaremos las enmiendas presentadas en el Senado por los nacionalistas vascos y catalanes por ser una reiteración de las que se presentaron en el Congreso de los Diputados, al igual que los argumentos en pro y en contra que en ellas se esgrimieron. 
español, en el que reside la soberania» ${ }^{34}$. A esta redacción, que reconocía una sola soberania y la atribuía al pueblo español, se presentaron varias enmiendas.

Las de los nacionalistas vascos, tanto moderados (PNV) como radicales (EE), intentaban expresar que los poderes del Estado emanan de los pueblos que lo forman o componen, en los que reside la soberania ${ }^{35}$. Esta fórmula permitía, como expusieron los propios enmendantes, la existencia de varias soberanías originales que creaban una nueva soberanía, la del Estado español y apuntaba a una solución confederal como forma de Estado ${ }^{36}$. Retirada la enmienda del señor Letamendia (EE), la del Grupo Vasco sólo obtuvo el voto a favor del representante en Comisión de dicho Grupo, 32 votos en contra y dos abstenciones ${ }^{37}$.

Más aséptica era la fórmula que proponían el Grupo Mixto y el señor Barrera, de Esquerra Republicana de Catalunya (ERC): la soberanía reside en el pueblo y de él emanan los poderes del Estado ${ }^{38}$. Sin embargo, al menos la presentada por el señor Barrera (ERC), tenia la misma finalidad que las anteriormente expuestas ${ }^{39}$. En este caso, no se adjetivaba el sus-

${ }^{34}$ Boletín Oficial de las Cortes, núm. 44, 5 de enero de 1978, p. 670.

35 Enmienda núm. 64 (señor Letamendia): «Los poderes de todos los organos del Estado emanan de los pueblos que lo componen, en los que reside la soberanía" (Constitución Española. Trabajos parlamentarios, Cortes Generales, Madrid 1980, t. I, p. 165). La enmienda núm. 590, del Grupo Vasco, sólo sustituía el verbo "componen" por «forman» (op. cit., t. I, p. 364).

${ }^{36}$ Como defendió el señor Arzallus (PNV), «la estructuración superior se forma a partir de soberanias originarias que ceden parte de su propia soberanía originaria para conformar esa estructura superior" (D.S.C.D., Comisión Constitucional, num. 64, 11 de mayo de 1978, p. 2183). Por su parte, el señor Letamendia (EE) explicó que «la redacción de la enmienda presentada por mí apunta a una estructura confederal del Estado español, es decir, a una estructura en la que los poderes originarios residen en los pueblos y los pueblos pueden hacer dejación de soberanía al Estado español» (D.S.C.D., Comisión Constitucional, núm. 64, 11 de mayo, p. 2182).

${ }_{37}$ D.S.C.D., Comisión Constitucional, núm. 64, 11 de mayo de 1978, p. 2190.

38 Enmienda núm. 241 (señor Barrera): «Los poderes de todos los órganos del Estado emanan del pueblo, en el que reside la soberania» (Constitución Española. Trabajos parlamentarios, Cortes Generales, Madrid 1980, t. I, p. 242). Curiosamente, aunque como señaló el proponente por diferentes motivos y justificaciones, esta enmienda coincidía literalmente con la que presentó el diputado de A. P., señor Carro (enmienda núm. 2) (Constitución Española..., t. I, p. 122). La enmienda núm. 454 (Grupo Mixto) proponia, por su parte, el siguiente texto: "La soberanía reside en el pueblo y de él emanan los poderes del Estado, que los ejercen conforme a la Constitución» (Constitución Española..., t. I, p. 315).

${ }^{39}$ En su intervención ante la Comisión, el señor Barrera (ERC) no tuvo ningún reparo en reconocer que su enmienda «parte en realidad de unos puntos de vista idénticos a los defendidos por el señor Letamendia y por el portavoz del Grupo Vasco. Mi redacción era, probablemente, algo más aceptable para una amplia ma- 
tantivo pueblo con lo que la interpretación del texto podía resultar posteriormente más flexible. Esta solución fue incorporada a una enmienda in voce que presentó en el debate en Comisión el Grupo Socialistes de Catalunya ${ }^{40}$. Retiradas las demás enmiendas, la socialista consiguió 16 votos a favor, aunque hubo 19 votos en contra ${ }^{41}$.

En el Pleno de la Cámara la enmienda del Grupo Vasco consiguió nueve votos a favor (presumiblemente los ocho representantes del PNV y el representante de EE) y 31 abstenciones (fundamentalmente de Minoría Catalana, ERC y Grupo Mixto). La enmienda del señor Barrera (ERC) obtuvo nueve votos a favor (el suyo y quizá los ocho del PNV) y 123 abstenciones (probablemente el resto de los nacionalistas y grupos socialistas del Congreso) ${ }^{42}$. Como se observa, los socialistas cambiaron el sentido de su voto en la Comisión, pues, aunque no se trataba de su enmienda, el contenido de la enmienda del señor Barrera era, como hemos visto, idéntico.

De estos debates hay que destacar dos aspectos:

- El silencio de los nacionalistas moderados de Cataluña que, aunque presumiblemente no votaron en contra de las propuestas nacionalistas, les distanciaba de los planteamientos más combativos de los nacionalistas vascos.

- Que ya en este aspecto tangencial respecto de la autodeterminación queda patente el consenso constitucional fraguado entre todos los partidos importantes y en el que participan los nacionalistas moderados catalanes.

b) La autodeterminación y el artículo 2 de la Constitución

Si en el debate del artículo 1.2 se trataba indirectamente de la autodeterminación, el diputado señor Letamendía (EE) presentó una enmien-

yoria en esta Cámara» (D.S.C.D., Comisión Constitucional, núm. 64, 11 de mayo de 1978, p. 2184).

40 La enmienda decía: «La soberanía reside en el pueblo, del que emanan todos los poderes del Estado" (D.S.C.D., Comisión Constitucional, núm. 64, 11 de mayo de 1978, p. 2187).

41 D.S.C.D., Comisión Constitucional, núm. 64, 11 de mayo de 1978, p. 2190.

42 D.S.C.D., Pleno, núm. 103, 4 de julio de 1978, p. 3792. 
da al artículo 2 del Anteproyecto de la Ponencia ${ }^{43}$, según la cual el citado artículo debía de redactarse así: «La Constitución se fundamenta en la plurinacionalidad del Estado español, la solidaridad entre sus pueblos, el derecho a la autonomia de las regiones y naciones que lo integran y el derecho a la autodeterminación de estas últimas" " ${ }^{44}$. En apoyo de su intento de constitucionalizar el derecho de autodeterminación el citado diputado expuso que un demócrata puede defender dos opciones totalmente válidas, la permanencia en un mismo Estado o la formación de un Estado propio; pero lo que no puede hacer es negar la existencia misma del derecho a esa opción ${ }^{45}$. Sin embargo, el proponente, tras su derrota en Comisión, retiró su enmienda al ser debatida en el Pleno, señalando que sometería a votación «el derecho de autodeterminación al defender la inclusión de un nuevo Titulo, el VIII bis» ${ }^{46}$.

Debe observarse también, que al artículo 2 del Anteproyecto se presentaron sendas enmiendas por parte de los grupos parlamentarios Catalán ${ }^{47}$ y Vasco ${ }^{48}$. En ambas, la autonomía de las regiones y nacionalidades, en lugar de ser reconocidas por la Constitución, constituyen uno de los fundamentos de la misma. Sin embargo, no parecen enmiendas rupturistas con la forma de Estado que se estaba dibujando en la Constitución.

El Grupo Vasco iba un poco más allá y rehusaba fundamentar la Constitución en la unidad de España. De ahí que lo hicieron directamente en la unión de las nacionalidades y regiones. Se trataba, en nuestra opinión, de evitar la expresión “unidad de España» que sonaba a concepto sagrado y perpetuo. El término «unión» imprimía un carácter más circunstancial, pasajero, revocable a la realidad que describia.

43 Artículo 2: «La Constitución se fundamenta en la unidad de España y la solidaridad entre sus pueblos y reconoce el derecho a la autonomía de las nacionalidades y regiones que la integran".

${ }^{44}$ Curiosamente el texto de su enmienda no fue incluida en la documentación que se facilitó a los diputados y tampoco aparece recogida en la obra editada por las Cortes Generales sobre los trabajos parlamentarios constituyentes. Por ello, fue el propio señor Letamendía quien tuvo que leer su enmienda ante la Comisión Constitucional para que la conocieran sus miembros (D.S.C.D., Comisión Constitucional, núm. 66, 12 de mayo de 1978, p. 2263).

${ }_{45}$ D.S.C.D., Comisión Constitucional, núm. 66, 12 de mayo de 1978, p. 2264.

46 D.S.C.D., Comisión Constitucional, núm. 103, 4 de julio de 1978, p. 3821.

47 Enmienda núm. 104: «La Constitución se fundamenta en la unidad de España, la solidaridad entre sus pueblos y el derecho a la autonomía de las nacionalidades y regiones que la integran" (Constitución Española. Trabajos Parlamentarios, Cortes Generales, Madrid 1980, t. I, p. 194). La del PCE, formulada en los mismos términos, en Constitución Española..., t. I, p. 424.

48 Enmienda núm. 591: «La Constitución se fundamenta en la unión, la solidaridad y el derecho a la autonomía de las naciones y regiones que integran España" (Constitución Española. Trabajos Parlamentarios, Cortes Generales, Madrid 1980, t. I, p. 365). 
Sin embargo, en el debate de este artículo tampoco quedó reflejada con claridad la postura de los diversos nacionalistas. Los argumentos y las enmiendas, al referirse a conceptos etéreos, favorecieron la ya pródiga ambigüedad de estos grupos. Donde sí pudieron determinarse con claridad fue en el segundo intento del señor Letamendia de constitucionalizar el derecho de autodeterminación.

\section{c) El intento de incorporación a la Constitución del procedimiento de autodeterminación}

Fracasados los intentos de incorporar el derecho de autodeterminación en el frontispicio de la Constitución, el diputado señor Letamendía (EE) planteó la enmienda número 64 con la que se pretendia incorporar un nuevo Título a la Constitución española en el que se constitucionalizara, tras la regulación del Estado autonómico, el procedimiento mediante el cual las regiones que así lo acordaran, tras dos años de vigencia de su Estatuto de Autonomía, pudieran autodeterminarse ${ }^{49}$. La propuesta fue derrotada en Comisión por 24 votos en contra y uno a favor (PNV) y fue significativa la ausencia del representante de Minoría Catalana que, sin embargo, intervino ante la Comisión Constitucional para aclarar que de haber estado presente no hubiese votado a favor de la enmienda del señor Letamentía ${ }^{50}$, aunque, como ha señalado SOLÉ TURA, mantuvo la duda de si habría votado no o se habria abstenido ${ }^{51}$.

El único voto a favor fue del Partido Nacionalista Vasco pero su portavoz manifestó que «el Partido Nacionalista Vasco ha votado sí al derecho de autodeterminación como tal derecho teórico, pero no a su constitucionalización. Si el Partido Nacionalista Vasco hubiera querido constitucionalizar el derecho de autodeterminación, hubiese presentado una enmienda en tal sentido. Pero las vías del Partido Nacionalista Vasco para conseguir las mayores cotas de libertad para nuestro pueblo van por otro camino" ${ }^{52}$. Más explícita no podía quedar la postura de los nacionalistas moderados vascos en relación con la autodeterminación.

Por su parte, la ambigüedad del representante catalán en la Comisión Constitucional quedó diluida al debatirse la enmienda en el Pleno del Congreso. El señor Trías, del Grupo Parlamentario Minoria Catalana, ex-

49 Op. cit., t. I, p. 173.

so D.S.C.D., Comisión Constitucional, núm. 91, 16 de junio de 1978, p. 3433.

${ }^{51}$ J. SolÉ TuRA: Nacionalidades y nacionalismos en España. Autonomías, federalismo, autodeterminación, Alianza Editorial, Madrid 1985, p. 139.

${ }_{52}$ D.S.C.D., Comisión Constitucional, núm. 91, 16 de junio de 1978, p. 3430. 
plicó que su grupo se había abstenido porque con ello habían votado a favor del derecho de autodeterminación como principio general y en contra de una enmienda que, basada en dicho principio, conducía a soluciones que no compartían ${ }^{53}$. En este sentido matizó: «No hemos votado la enmienda del señor Letamendía por razones obvias, porque nos ha parecido que la enmienda del señor Letamendia prejuzgaba un separatismo, es decir, que su autodeterminación llevaba un objetivo final separatista, que evidentemente no es el nuestro". Con la misma claridad expuso la postura sobre autodeterminación de su grupo político entendiendo que «la autodeterminación es un método, no un fin; es una manera de alcanzar unos resultados. $Y$ en ese sentido nosotros ya nos hemos autodeterminado. Nosotros somos partidarios de esta Constitución, que hemos votado y votaremos hasta el final y somos partidarios de la autonomia y de los Estatutos que este Parlamento, en su momento votará, y de nada más, absolutamente nada más». A pesar de la abstención y del respeto al principio general de autodeterminación, la postura parecía clara: sus aspiraciones políticas culminaban con la consecución de la autonomia política dentro del Estado español.

d) Constitución y autodeterminación

En consecuencia, del análisis del debate constituyente y de la propia Constitución podemos obtener dos claras conclusiones:

a) Que existió un rechazo expreso a la constitucionalización del derecho de autodeterminación como derecho atribuible a colectividades integradas en el Estado español, no sólo por parte de las fuerzas de ámbito estatal, sino también en las más importantes fuerzas de ámbito regional.

b) Que la Constitución en este sentido es un cuerpo legal cerrado que impide que se ejercite el derecho de autodeterminación en el interior del Estado español. 
Los motivos que justifican esta última conclusión han provocado algunas discrepancias doctrinales. Algunos autores ${ }^{54}$ han señalado la actual redacción del artículo 2 de la Constitución española, que proclama que ésta "se fundamenta en la indisoluble unidad de la Nación española», como el precepto constitucional que bloquea la posibilidad jurídica del reconocimiento de la autodeterminación. En nuestra opinión tanta o más importancia tiene el articulo 1.2 que establece que “la soberanía nacional reside en el pueblo español, del que emanan los poderes del Estado". Y ello por dos razones:

a) La indisoluble unidad de la Nación española podria ser compatible con fórmulas de autodeterminación que no supusieran la ruptura de esa unidad, es decir, la independencia de una parte de los miembros de la Nación española. Debemos recordar al efecto dos cosas:

- Que hoy en día no podemos equiparar Nación y soberanía. Existen naciones sin soberania y Estados, que obviamente tienen soberanía, que están conformados por varias naciones.

- Que autodeterminación no es sinónimo de independencia, sino de libre decisión por un colectivo sobre su forma de organización política, social o económica. En este sentido, cabria la posibilidad de que una región determinara por si sola la forma de integrarse en la unidad, excluyendo la independencia. Bastaria con que se admitiera la existencia de algún tipo de soberanía en las Comunidades ${ }^{55}$. Todas estas regiones podrian incorporarse al Estado con autonomía administrativa o con autonomia política, o federándose o confederándose con el resto del Estado. En todos estos supuestos podria seguir hablándose de una unidad de la Nación española, con diferentes formas de integración de los pueblos que la forman.

b) Sólo si se establece una sola soberanía para todo el territorio no cabe que se adopten modelos de integración en una unidad política superior con el exclusivo criterio del territorio implicado. Por ello, en España, a pesar de que ha regido el principio dispositivo en la configuración del Estado autonómico, la norma básica de cada Comunidad, donde se

${ }^{54}$ Así el profesor DE ESTEBAN en «Derecho a la autodeterminación y simulación política", en EI Mundo, 18 de diciembre de 1989, p. 8. En el mismo sentido, I. Cavero: «La Constitución ante la autodeterminación", en Revista de la Facultad de Derecho de la Universidad Complutense, núm. 15, 1989, pp. 319 a 334.

${ }_{55}$ Sobre las diversas formas de entender la convivencia de soberanias en los Estados federales o cuasi-federales, vid. M. GARCIA-PELAYo: Derecho Constitucional Comparado, Alianza Editorial, Madrid 1984, pp. 215-246. 
establece el modelo de integración en el Estado ${ }^{56}$, ha necesitado del debate y aprobación, tras las modificaciones pertinentes, de las Cortes Generales.

Sin embargo, como ya hemos señalado, el derecho a la autodeterminación de los pueblos forma parte de nuestro ordenamiento jurídico como consecuencia de lo establecido en el artículo 96 de la Constitución. Pero no puede desprenderse de ello que el derecho de autodeterminación pueda ser aplicable a los pueblos que componen España, ya que el artículo 95 de la Constitución establece que la celebración de un tratado internacional que contenga estipulaciones contrarias a la Constitución exige la previa revisión constitucional.

Parece evidente que el Estado español participa de la interpretación que la Asamblea General de Naciones Unidas ha dado del derecho de autodeterminación, entendiendo que únicamente los pueblos sometidos a dominación colonial pueden disfrutar de este derecho ${ }^{57}$ y que su ejercicio nunca legitima una acción encaminada a quebrantar o menoscabar, total o parcialmente, la integridad territorial de los Estados soberanos e independientes ${ }^{58}$.

De haber asumido otra interpretación, para incorporar dichos Pactos a nuestro ordenamiento debiera de haberse modificado el texto constitucional. Como mantiene el profesor DE ESTEBAN una interpretación diferente del artículo 1 de dicho Pacto acarrearia la reforma de la Constitución en el momento en que se aceptara ésta ${ }^{59}$.

Recapitulando, baste decir que los artículos 1.2 y 2 de la Constitución impiden el reconocimiento del derecho de autodeterminación para los pueblos que componen España. Y que, aunque el derecho de autodeterminación forma parte del ordenamiento jurídico español, se ha interpretado de manèra que no pueda ser atribuido a éstas. Otra interpretación colisionaría con la redacción de los precitados articulos constitucionales y para que tuviera eficacia juridica en España deberian ser modificados con anterioridad ambos artículos.

56 Hay que recordar a este respecto que los Estatutos que siguieron la vía del artículo 143 de la Constitución podían haberse incardinado en el Estado con un sistema de mera descentralización administrativa.

${ }_{57}$ «Declaración sobre la concesión de la independencia a los países y pueblos coloniales", Resolución 1514 (XV), de 14 de diciembre de 1960, de la Asamblea General de la Organización de Naciones Unidas.

58 "Declaración sobre los Principios de Derecho Internacional referentes a las Relaciones de Amistad y a la Cooperación entre los Estados de conformidad con la Carta de las Naciones Unidas», Resolución 2625 (XXV), de 24 de octubre de 1970, de la Asamblea General de la ONU.

59 J. DE ESTEBAN: «Derecho a la autodeterminación y simulación política», en El Mundo, 18 de diciembre de 1989, p. 8. 


\section{LA RECIENTE REIVINDICACIÓN DEL DERECHO A LA AUTODETERMINACIÓN EN ESPAÑA}

Tras la aprobación de la Constitución, la reivindicación de la autodeterminación siguió presente en la vida política, aunque en un segundo plano. Ha sido una aspiración propugnada por fuerzas extraparlamentarias en Cataluña y, hasta el momento de la aparición de Eusko Alkartasuna, por el grupo terrorista ETA y su supuesta filial política, Herri Batasuna, en el País Vasco.

Sin embargo, este derecho ha sido debatido recientemente por diversas Cámaras regionales a partir de una primera proposición no de ley presentada por Esquerra Republicana de Cataluña (ERC) en el Parlamento de esta Comunidad Autónoma. Vamos a limitarnos a estudiar la tramitación y los acuerdos adoptados en los Parlamentos catalán y vasco, ya que las otras iniciativas que se produjeron en otras Asambleas regionales ${ }^{60}$, además de que no prosperaron, tampoco aportaron nada destacable respecto de las que sí fueron aprobadas.

\section{a) La proposición no de ley del Parlamento de Cataluña}

Efectivamente, la problemática de la reivindicación autodeterminista sufrió una sustancial modificación cuando, con motivo del décimo aniversario de la aprobación del Estatuto de Autonomia de Cataluña, Esquerra Republicana de Catalunya (ERC) presentó una proposición no de ley sobre el derecho de autodeterminación de la nación catalana. Lo que parecía un gesto testimonial de una formación minoritaria, se convirtió en el origen de una importante crisis politica en el Estado español.

Analicemos, pues, dicha Resolución y los debates parlamentarios para, a continuación, poder extraer las oportunas consideraciones.

60 Así, la proposición no de ley que se presentó en el Parlamento gallego por el Grupo Parlamentario Mixto a iniciativa del diputado del Partido Socialista Gallego-Esquerda Galega, señor Nogueira Román (Boletín Oficial Parlamento de Galicia, III Legislatura, núm. 9, 23 de febrero de 1990, pp. 83-86), y la proposición no de ley que formuló ante el Parlamento canario el Grupo Parlamentario Mixto a instancia de los diputados de Asamblea Canaria Nacionalista (Boletín Oficial del Parlamento de Canarias, II Legislatura, núm. 35, 16 de marzo de 1990, pp. 420-422). La iniciativa de Unitat del Poble Valenciá ante las Cortes Valencianas no llegó a ser publicada pues fue rechazada por la Mesa de la Cámara el 2 de febrero de 1990. 
1. La tramitación y debate de la proposición no de ley.

La proposición no de ley ${ }^{61}$ presentada por Esquerra Republicana de Catalunya, tras una breve pero sustanciosa exposición de motivos, proclamaba:

- Que Cataluña es una nación (apartado 1).

- Que el acatamiento del marco estatutario no supone una renuncia del pueblo catalán a sus derechos históricos (apartado 2).

- Y en consecuencia, el derecho legítimo y democrático del pueblo catalán a ejercer su derecho a la autodeterminación nacional que habrá de permitir a los catalanes "escoger, sin limitaciones de ningún tipo, el futuro político de la nación catalana y sus relaciones con los otros pueblos, en el marco de una Europa unida, libre y solidaria, desde el Atlántico a los Urales" (apartado 3).

Por la Agrupación Parlamentaria del Centro Democrático y Social se presentaron dos enmiendas de supresión que afectaban a los apartados 2 y 3 de la propuesta de proposición no de ley ${ }^{62}$.

Por su parte, Convergència i Unió presentó una enmienda de modificación ${ }^{63}$ del texto de la propuesta en los siguientes aspectos:

- Sustituía la afirmación tajante de que Cataluña es una nación por la fórmula aparentemente suavizada de que "Cataluña forma parte de una realidad nacional diferenciada en el conjunto del Estado".

- Mantenía que el acatamiento del marco institucional vigente «no significa la renuncia del pueblo catalán a decidir por sí mismo la libertad colectiva de su pais" pero, matizaba, «de acuerdo con el derecho inalienable al autogobierno".

61 Butlleti Oficial del Parlament de Catalunya, núm. 106, 6 de noviembre de 1989, pp. 6818 y 6819 .

62 Ibidem, núm. 117, 13 de diciembre de 1989, p. 7681.

63 Ibidem, núm. 117, 13 de diciembre de 1989, p. 7681. 
- Establecia que a través de los procedimientos previstos en el ordenamiento constitucional, Cataluña podrá incrementar las cotas de autogobierno.

Con la enmienda se eliminaba el término «autodeterminación» y se buscaba conseguir un texto más ambiguo que pudiera satisfacer tanto al grupo proponente como a los grupos políticos de ámbito estatal representados en la Cámara. Para los primeros, la afirmación de que el pueblo catalán debe decidir por sí mismo la libertad colectiva de su pais o la referencia al aumento del autogobierno podían identificarse con las aspiraciones autodeterministas. Para los segundos, estos términos podían entenderse como una ampliación del marco competencial autonómico sin afectar a la estructura del Estado. Convergència i Unió repetía la ambigüedad del debate constitucional, intentando abarcar el máximo electorado posible e intentando contentar a las fuerzas políticas de su entorno. Asi las cosas, el acuerdo del Parlamento haciendo suya la propuesta de Convergència i Unió no iba a suponer más que una nueva afirmación de la voluntad de autogobierno del pueblo catalán.

Pero llegado el día del debate en la Comisión correspondiente ${ }^{64}$, Convergència i Unió presentó una enmienda transaccional, pactada con el grupo proponente (ERC), en la que, tomando como base la enmienda de modificación presentada en su día por Convergència, sustituia en el segundo punto la expresión "derecho al autogobierno" por "derecho a la autodeterminación» ${ }^{65}$.

Obsérvese que, aunque sólo se produce una modificación respecto de la enmienda de Convergència, es de tal importancia que modifica el sentido del tercer apartado aunque mantenga éste la misma redacción. Así al hablar de autodeterminación ya no se puede jugar con el ambiguo término «autogobierno». La autodeterminación significa soberanía por lo que el párrafo tercero ya no se puede tomar como una referencia a la ampliación competencial ceñida a la reforma del Estatuto. La referencia a la utilización de procedimientos recogidos en la Constitución ya sólo podía referirse a la reforma de la Carta Magna.

Para despejar dudas respecto al sentido final de la proposición no de ley, el portavoz de Esquerra Republicana, al explicar su aceptación de la enmienda transaccional manifestó que «el ordenamiento constitucional implica siempre la posibilidad de reforma y con la reforma implica... la posibilidad de que un día este ordenamiento constitucional pueda incluir el

64 Se trataba de la Comisión de Organización y Administración de la Generalidad y Gobierno Local.

65 Diari de Sessions, C, núm. 102, 12 de diciembre de 1989, pp. 2023-2024. 
derecho a la autodeterminación de las naciones que configuran el actual Estado español" ${ }^{66}$.

Sólo el Grupo Socialista se opuso a la transaccional que fue votada afirmativamente hasta por el Grupo del Centro Democrático y Social que había planteado en principio dos enmiendas de supresión de dos apartados ${ }^{67}$, aunque con la ausencia de los representantes del Partido Popular. El Grupo Socialista propuso, evidentemente sin éxito, que se abandonara la tramitación de la proposición no de ley y se siguiera la vía de reforma estatutaria para adquirir nuevas competencias ${ }^{68}$.

luña ${ }^{69}$ manifestaba:

Consecuentemente, la Resolución 98/III del Parlamento de Cata-

- Que Cataluña es parte de una realidad nacional diferenciada dentro del Estado español.

- Que el acatamiento del marco institucional no significa la renuncia del pueblo catalán al derecho de autodeterminación, «tal como establecen los principios de los organismos internacionales y se deduce del preámbulo del Estatuto...».

- Que consecuentemente, a través de las actuaciones previstas en el ordenamiento constitucional, se podrá incrementar las cotas de autogobierno y adecuar la regulación de los derechos nacionales a las circunstancias de cada momento histórico. de ley.

2. Conclusiones sobre el debate y aprobación de la proposición no

66 Diari de Sessions, C, núm. 102, 12 de diciembre de 1989, p. 2025.

${ }^{67}$ La decisión del portavoz de la Agrupación parlamentaria del Centro Democrático y Social es llamativamente incongruente. Tras expresar que no son favorables a la autodeterminación y mantener que por ello se oponian a los apartados 2 y 3 de la propuesta de Esquerra Republicana de Catalunya, explica que habian pensado apoyar los párrafos 1 y 3 de la primera enmienda de Convergència. De ésta rechaza el punto 2 que, como se recordará, habla de profundización en el autogobierno. Pero termina manifestando que va a votar a favor de una transaccional, que como hemos visto incorpora el término autodeterminación, porque "es conforme con nuestras posiciones" (Diari de Sessions, C, núm. 102, 12 de diciembre de 1989, p. 2024).

68 Diari de Sessions, C, núm. 102, 12 de diciembre de 1989, p. 2025.

69 Butlleti Oficial del Parlament de Catalunya, núm. 120, 18 de diciembre de 1989, pp. 7791-7792. 
Como consecuencia de lo manifestado por los diferentes grupos parlamentarios a lo largo del debate y del propio texto de la proposición aprobada, cabe destacar lo siguiente:

- Tal como dijo el portavoz de los comunistas catalanes, el texto de la transaccional era un hábil ejercicio de redacción que desmochó las lanzas afiladas de la proposición inicial ${ }^{70}$. Pero, con todo, se cumple el objetivo inicial de la propuesta de ERC: que se reivindique el derecho de autodeterminación de Cataluña.

- La Resolución aprobada parece que rebaja la dureza de la propuesta inicial al no hablar directamente de Nación, término no admitido por la Constitución española para referirse a la población de una Comunidad Autónoma. Sin embargo, la nueva redacción supone que el Parlamento catalán considera que Cataluña es parte de una realidad nacional diferenciada dentro del Estado español. Es decir, el Parlamento catalán asume el planteamiento de los independentistas catalanes ${ }^{71}$ de que Cataluña forma parte de lo que se ha denominado «Paises Catalanes» y que incluye a la Comunidad Valenciana, las Islas Baleares y el Rosellón francés. En este sentido, el portavoz de Esquerra Republicana, al justificar la aceptación de la transaccional de Convergència i Unió, aclaró que el texto de la enmienda «puede ser que precise más la declaración solemne de que formamos parte de la realidad nacional, entendiendo el global de los Países Catalanes» ${ }^{72}$.

- Que se trata de un texto incongruente. Dado que se intentó mantener la enmienda transaccional lo más parecida a la primera enmienda de Convergència, se justifica la reivindicación del derecho de autodeterminación en los principios de los organismos internacionales y en el preámbulo del Estatuto de Autonomía. Esta referencia que era coherente cuando se utilizaba el término "autogobierno", no es de recibo cuando se habla de derecho de autodeterminación pues ni los principios de los organismos internacionales amparan, tal como hemos visto, el derecho de autodeterminación para un pueblo que disfruta de autogobierno y está integrado en

70 Diari de Sessions, C, núm. 102, 12 de diciembre de 1989, p. 2024.

$"$ En la exposición de motivos de la proposición no de ley presentada por Esquerra Republicana se señalaba como una de las causas de la presentación de la misma, que Cataluña, en el marco de los Países Catalanes, debe contribuir a la construcción de una nueva Europa, basada en una comunidad de pueblos iguales, libres y solidarios (Butlletí Ofícial del Parlament de Catalunya, núm. 106, 6 de noviembre de 1989 , p. 6819).

72 Diari de Sessions, C, núm. 102, 12 de diciembre de 1989, p. 2025. 
un Estado democrático, ni el preámbulo del Estatuto hace más referencia que al autogobierno ${ }^{73}$.

- Que los propios defensores del derecho de autodeterminación para Cataluña intuían que su celo nacionalista podía no ser compartido por el pueblo catalán. En este sentido, son clarificadoras las intervenciones del portavoz del grupo comunista, quien manifestó que, «por desgracia, nos parece que esta conciencia mayoritaria de los ciudadanos y las ciudadanas de Cataluña como nación, no es del todo clara..." ${ }^{74}$, y del portavoz de Esquerra Republicana quien dijo que el derecho de autodeterminación «por desgracia no es todavía sentido por un conjunto total o muy mayoritario o percibido así por la población de Cataluña, por su totalidad» ${ }^{75}$.

\section{b) La proposición no de ley del Parlamento Vasco}

Pero, con todo, la aprobación por la Comisión correspondiente del Parlamento catalán de la proposición no de ley autodeterminista no fue el hecho más señalado de la crisis política que se vivió al inicio de la década de los noventa.

Inmediatamente, surgió el temor de que se reprodujera una declaración de este estilo en el Parlamento Vasco. Era evidente que, con la presión terrorista, el debate podía envenenarse y multiplicar su efecto desestabilizador. Por ello, el Partido Socialista no dudó en presionar sobre su coaligado en el Gobierno regional para evitar que prosperara una iniciativa en dicho sentido. Presiones que llegaron a su cenit cuando el presidente del Senado y el propio presidente del Gobierno manifestaron a la prensa $^{76}$ la posibilidad de que quedara en suspenso el Estatuto del Pais Vasco en aplicación de las medidas extraordinarias que prevé el artículo 155 de la Constitución española.

Sin embargo, de poco sirvieron estas presiones. Se tramitaron no una sino dos proposiciones no de ley. Vamos a seguir en este caso el mismo

73 Esta incongruencia fue también denunciada por el profesor ApARIcio en El Pais, 15 de diciembre de 1989, p. 22.

${ }_{74}$ Diari de Sessions, C, núm. 102, 12 de diciembre de 1989, p. 2024.

75 Ibidem, C, núm. 102, 12 de diciembre de 1989, p. 2025.

76 Las declaraciones del presidente del Senado en El Independiente, 13 de enero de 1990, p. 5. Las declaraciones del presidente del Gobierno fueron recogidas por todos los medios de comunicación social (por todos, El País, 7 de enero de 1990, p. 13). 
procedimiento de análisis que hemos adoptado para la proposición no de ley catalana.

1. La tramitación y debate de la proposición no de ley.

Como deciamos, a pesar de todo, con fecha 5 de enero de 1990 se presentaron dos proposiciones no de ley sobre el derecho de autodeterminación del pueblo vasco. Una formulada por los Grupos parlamentarios del PNV y Euskadiko Ezkerra ${ }^{77}$ y otra suscrita por Eusko Alkartasuna ${ }^{78}$.

El contenido de la primera de ellas, esencialmente, era el siguiente:

a) El pueblo vasco tiene derecho a la autodeterminación, derecho que consiste en decidir libre y democráticamente su situación política, económica, social y cultural, «bien dotándose de un marco político propio o compartiendo, en todo o en parte, su soberania con otros pueblos».

b) El ejercicio de dicho derecho es un proceso gradual integrado por las decisiones que el pueblo vasco vaya adoptando a lo largo de su historia.

c) El Estatuto es, «aquí y ahora, la única vía de plasmación del ejercicio de la voluntad popular» pues es el marco libremente aprobado por los ciudadanos vascos para resolver sus problemas.

d) El Parlamento vasco es el único legitimado para promover «las reformas de todo tipo que considerase oportunas de conformidad con los procedimientos establecidos al efecto".

Este texto de la proposición no de ley quedaba mitigado por la previa y extensa exposición de motivos en la que se afirmaba, entre otras cosas, que:

${ }^{7}$ Boletin Oficial del Parlamento Vasco, III Legislatura, núm. B-IV-134 (a) alea, 22 de enero de 1990.

78 Ibidem, III Legislatura, núm. B-IV-135 (a) alea, 22 de enero de 1990. 
a) «La reducción del principio de autodeterminación exclusivamente a una decisión a adoptar en un momento en torno a una disyuntiva no sólo no se adecua a la complejidad de la sociedad actual, sino que puede terminar por negar el sentido profundo de ese mismo principio, en tanto que puede restringir la libertad en su proyección histórica».

b) «La reducción del principio de autodeterminación exclusivamente al establecimiento de un marco jurídico-positivo de relación con los demás no responde a la complejidad de cuestiones que la sociedad vasca ha de resolver en el panorama cambiante de la Europa actual» pues "la construcción de Euskadi como nación no permite la periódica puesta en cuestión de los niveles de democracia y autogobierno logrados hasta ahora, máxime si ese cuestionamiento se formula sin alternativas reales en cuanto que socialmente asumidas, y sin el consenso político suficiente».

c) «Cualquier momento puede ser oportuno para elevar cualquier propuesta de reforma estatutaria o constitucional, pero sin duda es exigible que el sentido de la responsabilidad obligue a propuestas concretas expresadas claramente, y no a propuestas genéricas o planteadas de manera indiscriminada».

Por su parte, la proposición no de ley presentada por Eusko Alkartasuna, tras una larga exposición de motivos en la que se decia, entre otras cosas, «que el pueblo vasco constituye una nación a la que, como tal, le ha de ser reconocido el derecho de libre determinación y que sus ciudadanos han de poder ejercerlo, decidiendo libremente y sin injerencia ni límite externo su forma de organización política, sea a modo de integración en la organización u organizaciones políticas de otros pueblos, sea a modo de configuración de un Estado propio, sea a modo de otras formas intermedias o diversas, particularmente las que resulten del proceso de formación política de Europa», proclamaba que:

a) El Estatuto de autonomía supuso la única opción posible en la transición española y, además, es una vía inicial válida para la construcción nacional de Euskadi.

b) Pese a la aceptación del régimen estatutario se afirmaba que:

- Euskadi es una nación integrada por los territorios del Pais Vasco francés y español y por Navarra y como tal tiene derecho a la unidad política territorial. 
- «El pueblo vasco tiene derecho a la autodeterminación y los ciudadanos han de poderlo ejercitar soberanamente, sin ninguna limitación externa".

- El derecho de autodeterminación implica la posibilidad de optar por la creación de un Estado.

- Por ello han de iniciarse negociaciones con el Estado español para la incorporación del derecho de autodeterminación en el marco legal español.

c) Se rechazaba de cualquier estrategia violenta para la consecución de dichos objetivos.

Las reacciones en el ámbito abertzale y no nacionalista no se hicieron esperar. Por un lado, Herri Batasuna anunció su presencia en el Parlamento vasco y presentó una enmienda de totalidad ${ }^{79}$ que era una refundición de aspectos de las dos proposiciones anteriores, con añadidos propios:

a) Asumía que Euskadi es una nación integrada por los territorios que enumeraba la proposición de EA.

b) Se reiteraba la definición de autodeterminación de la proposición del PNV.

c) Se reproduce que una posibilidad derivada del derecho de autodeterminación es la de crear un Estado (propuesta de EA). torial.

d) Se añade que Euskadi tiene derecho a la unidad político-terri-

79 Las enmiendas no son publicadas en el Boletín Oficial del Parlamento del País Vasco. Trabajamos sobre fotocopias del escrito de presentación de la enmienda que tuvo entrada en el Parlamento Vasco el 8 de febrero de 1990, con el número 6128, y que ha sido facilitado por el propio Parlamento Vasco. 
En consecuencia, la proposición no de ley requiere a la Comunidad internacional, en particular a la Comunidad Europea y a los Estados español y francés, el reconocimiento de los derechos a la unidad político-territorial y a la autodeterminación.

La gran diferencia de las enmiendas de estos dos partidos respecto de las proposiciones no de ley presentadas, estriba en que, junto a la formulación y reclamación teórica del derecho de autodeterminación, añaden un último punto que supone el inicio de acciones encaminadas a que se reconozca el derecho por el ordenamiento español (EA) o por la Comunidad internacional (HB). Es por ello por lo que parecen más coherentes que otras propuestas, puesto que no tiene sentido reclamar un derecho sin que, al propio tiempo, se haga algo para conseguir su efectividad.

Por el sector de partidos no nacionalistas ${ }^{80}$, únicamente el Partido Popular presentó una radical enmienda de totalidad ${ }^{81}$. En ella se afirmaba que la soberanía nacional y el derecho de autodeterminación corresponde al pueblo español, que la secesión de una parte de un Estado democrático es inviable por las prescripciones del Derecho interno e internacional y que la secesión, consecuencia última de la autodeterminación, se opone al compromiso político que condujo al Estatuto.

Sin embargo, los proponentes de las proposiciones (PNV, EE y EA) unieron sus fuerzas y redactaron una enmienda de totalidad ${ }^{82}$ conjunta que, finalmente, fue aprobada por el Parlamento Vasco. En realidad, como se puede deducir de su contenido, la enmienda conjunta supuso que Eusko Alkartasuna se plegara al planteamiento más moderado del PNV y EE. Prácticamente no se recoge nada de lo planteado en la proposición no de ley de Eusko Alkartasuna, salvo la proclama en favor del derecho de autodeterminación. El contenido de la enmienda, y por tanto de la proposición no de ley aprobada ${ }^{83}$, es el siguiente:

a) Asume íntegramente los dos primeros puntos de la proposición no de ley presentada por el PNV y EE, es decir, la proclamación de que el

80 Al menos no nacionalista vasco, pues, a lo largo del debate en el Parlamento Vasco, el Partido Popular fue calificado por varios intervinientes como grupo nacionalista español.

${ }_{81}$ Utilizamos fotocopia del escrito de presentación de la enmienda, con registro de entrada en el Parlamento Vasco número 6137, de fecha 8 de febrero de 1990.

82 Utilizamos fotocopia del escrito de presentación de la enmienda, con registro de entrada en el Parlamento Vasco número 6139, de fecha 8 de febrero de 1990.

в3 Boletín Oficial del Parlamento Vasco, III Legislatura, núm. B-IV-134-135(d) alea, de 26 de febrero de 1990. 
pueblo vasco tiene derecho a la autodeterminación y la afirmación de que su ejercicio es un proceso gradual.

b) Concluye que el Estatuto es expresión libre y legítima de la propia voluntad del pueblo vasco.

c) Afirma que siendo el pueblo vasco el titular del derecho a la libre determinación, son las instituciones representativas del País Vasco, especialmente el Parlamento Vasco, las únicas legitimadas para impulsar su ejercicio, promoviendo las reformas de todo tipo que considerase oportunas, de conformidad con los procedimientos establecidos al efecto.

4. Conclusiones derivadas de la proposición no de ley aprobada por el Parlamento Vasco.

El debate en el Parlamento Vasco fue más intenso que el que se produjo en la Comisión del Parlamento de Cataluña. Todos los partidos, tanto los favorables a la proposición como los que se oponían a la misma, hicieron uso de toda su artillería dialéctica. Sin duda, en ello influyó que el debate fue conocido con antelación por la opinión pública y que se produjera una gran polémica nacional al respecto. Gracias a esta circunstancia podemos formular algunas consideraciones:

- El texto aprobado evitó aparecer como un texto radical. En ese sentido, obvió diversas afirmaciones que incluía la propuesta de Eusko Alkartasuna. Pero, con términos más suaves, mantuvo la quinta-esencia del debate: la proclamación del derecho de autodeterminación que posee el pueblo vasco y la interpretación de dicho derecho como la capacidad de darse, sin límite externo alguno, el marco político que estime conveniente ${ }^{84}$. Prueba de su radicalidad es el hecho de que la proposición no de ley propuesta por H.B. sólo se diferenciaba de la aprobada porque

${ }^{84}$ En este sentido, el portavoz de H.B. explicó que es correcta la definición del derecho de autodeterminación que se hace en la proposición aprobada pero que «se utiliza un lenguaje barroco y confuso y se mezclan contenidos y conceptos, precisamente con la finalidad de difuminar sus perfiles" (Diario de Sesiones del Parlamento Vasco, III Legislatura, núm. 55, alea, 15 de febrero de 1990, p. 24) 
ésta prescribia la via institucional para conseguir el derecho de autodeterminación ${ }^{85}$.

- Al asumirse la reivindicación del derecho de autodeterminación, se produjo un acercamiento de los nacionalistas moderados a las tesis de los grupos más radicales. Como dijo el portavoz de Herri Batasuna, mostrando el debate como un éxito propio, «hoy hemos conseguido el debate; mañana, la admisión del derecho, y al final, su aplicación» ${ }^{86}$.

- A pesar de los intentos de identificar autodeterminación con independencia de los representantes no nacionalistas ${ }^{87}$, los portavoces de los grupos nacionalistas rechazaron tal identificación.

- Los representantes de partidos estatales rechazaron la proposición, argumentando que el derecho de autodeterminación está reservado a países colonizados y que el pueblo vasco ya se ha autodeterminado con la Constitución y más concretamente con el Estatuto de Autonomía ${ }^{88}$. Sólo el Partido Popular recurrió tambien a argumentos históricos y sociológicos $^{89}$.

85 El señor truin, portavoz de H.B., concluyó su intervención diciendo «si bien asumimos sin reservas su punto primero (el de la autoenmienda), que afirma correctamente, como he dicho antes, el derecho a la autodeterminación del pueblo vasco, no admitimos que esta afirmación sea negada al proclamar que la via única para su reconocimiento es la existente, según ellos, dentro del juego institucional definido por la Constitución y el Estatuto" (Diario de Sesiones del Parlamento Vasco, ill Legislatura, núm. 55, alea, 15 de febrero de 1990, p. 27). En este mismo sentido el portavoz de Eusko Alkartasuna afirmó en el debate que su enmienda a la totalidad no era aceptable para H.B. «única y exclusivamente porque parte de una estrategia democrática que rechaza la violencia" (Diario de Sesiones del Parlamento Vasco, p. 37). Por su parte, el portavoz del PNV mantuvo que la enmienda presentada por H.B. era «una mera copia de lo presentado entre los tres grupos proponentes» (Diario de Sesiones del Parlamento Vasco, p. 42).

${ }^{86}$ Diario de Sesiones..., p. 23

87 En este sentido, vid. la intervención del portavoz del Grupo Popular (Diario de Sesiones del Parlamento Vasco, p. 28) y la del representante del CDS (Diario de Sesiones..., pp. 46 y 47 ).

as Portavoz de los socialistas vascos (Diario de Sesiones del Parlamento Vasco, pp. 48-50), portavoz del Grupo Popular (pp. 29-30), representante del Centro Democrático y Social (p. 47).

${ }^{89}$ Diario de Sesiones..., p. 28. 
c) Valoración global de las resoluciones autodeterministas aprobadas por los Parlamentos Vasco y de Cataluña

Evidentemente, la aprobación de estas proposiciones no de ley supuso la ruptura de los nacionalistas moderados con la postura que ellos mismos mantuvieron en el debate constituyente. En este sentido se puede hablar de una fractura del pacto constitucional, sobre todo en lo referente a los nacionalistas catalanes que tuvieron una mayor implicación en él.

Si bien es cierto que los nacionalistas vascos no se integraron en el consenso constitucional, no puede aceptarse que el portavoz del PNV en la Cámara vasca justificara el cambio de opinión respecto de la autodeterminación afirmando que «los nacionalistas vascos no aprobamos el texto constitucional. $Y$ en la Euskadi autónoma el referéndum constitucional quedó bajo mínimos. Así pues, el que hayamos acatado la Constitución y el que la sigamos acatando no implica el que la aprobáramos ni que la aprobemos hoy" ${ }^{90}$. Debemos recordar que, tal como hemos visto, el Partido Nacionalista Vasco no intentó incorporar el derecho de autodeterminación a la Constitución y rechazó expresamente dicha via para lograr cotas más amplias de libertad para el pueblo vasco. Hay que tener en cuenta que si este grupo político propugnó la abstención en el referéndum constitucional, no fue debido a que no se reconociera el derecho de autodeterminación pues tampoco ellos lo habian apoyado, sino porque no se aceptó el contenido que proponian para la Disposición Adicional 1. ${ }^{\mathrm{a}}{ }^{21}$.

Puesta de relieve la mutación en las posiciones de los nacionalistas moderados respecto del momento constituyente, debemos intentar hacer un catálogo de circunstancias que han favorecido este cambio de actitud respecto del derecho de autodeterminación.

\section{ANÁLISIS DE LAS RAZONES QUE LLEVARON AL REPLANTEAMIENTO DEL DERECHO DE AUTODETERMINACIÓN}

En nuestra opinión, han sido varias las cuestiones que han contribuido a que se produjeran estos acuerdos reivindicativos del derecho de autodeterminación. Pero al acometer el análisis de las causas hay que di-

90 Diario de Sesiones..., p. 41.

${ }^{91}$ J. SOlÉ TURA: Nacionalidades y nacionalismos en España. Autonomias, federalismo y autodeterminación, Alianza Editorial, Madrid 1985, p. 105. 
ferenciar dos momentos independientes. Por un lado, las razones que iniciaron el proceso de acuerdos autodeterministas. En segundo lugar, las razones que facilitaron que una iniciativa de un grupo minoritario (ERC) prosperara en el Parlamento de Cataluña y provocara que un acuerdo similar fuera adoptado por el Parlamento Vasco.

Respecto al primer hecho, dos son las causas que motivaron que se activara la espoleta del conflicto político:

Por un lado, las razones aducidas por Esquerra Republicana en la exposición de motivos de su proposición no de ley: la necesidad de recordar que el Estatuto no colma las aspiraciones del pueblo catalán y la ola de nacionalismo e independentismo que se produce en Europa ${ }^{92}$.

Por otro, creemos que dicha fuerza política tenía la necesidad de definir su nuevo espacio político ante la opinión pública después del congreso en el que había triunfado la línea independentista.

Las razones que provocaron la adhesión de los nacionalistas moderados fueron más diversas. Las hubieron comunes y especificas de cada Comunidad. Empezaremos por las comunes señalando las siguientes:

a) Desde el momento del debate constituyente se vio frustrada una aspiración que era compartida por muchos españoles, fundamentalmente por quienes participaron en la lucha antifranquista en Cataluña y el País Vasco. Como ha explicado SOLÉ TURA, y ya hemos expuesto al analizar el debate constitucional, la izquierda española hizo del derecho a la autodeterminación una bandera de lucha antifranquista. Sin embargo, llegado el momento constituyente, por razones pragmáticas ${ }^{93}$, abandonaron dicha legitimación. En este sentido el derecho de autodeterminación es una asignatura pendiente de la democracia española.

Hoy en día existe la impresión generalizada de que la presión que los poderes fácticos, fundamentalmente las Fuerzas Armadas, realizaron durante el proceso constituyente para evitar soluciones políticas que cuestionaran la unidad de España ${ }^{94}$ ha desaparecido y que éstas han aceptado su papel de instrumento al servicio de las decisiones políticas de la sociedad española.

${ }_{92}$ Butlleti Oficial del Parlamento de Catalunya, núm. 106, 6 de noviembre de 1989, p. 6819.

${ }_{93}$ A este respecto, SOLÉ TURA ha afirmado que «de haber votado la incorporación del derecho de autodeterminación tal como lo proponia el diputado señor Letamendía no habriamos tenido ni derecho de autodeterminación ni autonomias, y posiblemente ni Constitución» (Nacionalidades y nacionalismos en España..., Alianza Editorial, Madrid 1985, p. 140).

94 Son significativas las palabras del diputado señor Letamendía al defender 
b) También tuvo su importancia el hecho de que desde el momento constituyente se ha producido un fuerte ascenso electoral de las fuerzas nacionalistas. Evidentemente ciertas larvadas aspiraciones no podian mantenerse sin el respaldo de las tesis nacionalistas por parte de las poblaciones afectadas. Hoy, al menos en Cataluña y el Pais Vasco, se puede afirmar que una mayoria de la población vota nacionalista.

En Cataluña, hay que tener en cuenta que en las elecciones generales de 1977, que dieron lugar a la Asamblea constituyente, los partidos nacionalistas con representación parlamentaria lograron un moderado procentaje, el 21,3 por 100 de los votos emitidos, frente a los partidos estatales con presencia en las Cámaras que obtuvieron el 66,9 por $100^{95}$. Estos porcentajes han ido aumentando y en las elecciones generales de 1989 los partidos nacionalistas subieron hasta el 35,6 por 100 , mientras los grupos estatales descendieron al 58 por $100^{96}$.

Si las elecciones se circunscriben al ámbito regional, los nacionalistas logran mejores resultados. En 1988, las últimas elecciones autonómicas celebradas en Cataluña, los nacionalistas suponian el 50,1 por 100 de los votos emitidos. Por su parte, los partidos no nacionalistas con representación parlamentaria obtuvieron el 47,1 por 100 de los sufragios ${ }^{97}$.

Con respecto al Pais Vasco, si bien la fuerza de los nacionalistas era mayor en el momento constituyente, al contar con el 39,3 por 100 de los votos emitidos en aquella Comunidad, frente al 60,7 por 100 de los partidos estatales ${ }^{98}$, el aumento también ha sido fuerte: en las generales de 1989 obtuvieron el 59,1 por 100 de los votos emitidos, mientras los partidos estatales sólo sumaban el 36,5 por $100{ }^{99}$.

En 1986, en las elecciones que dieron lugar a la Cámara que hoy legisla en aquella Comunidad, la diferencia habia aumentado: los nacionalistas con representación parlamentaria suponian el 67,9 por 100 de los

ante el Pleno del Congreso la enmienda que intentaba introducir el procedimiento de ejercicio de la autodeterminación. Nada más comenzar su intervención solicitó de los miembros de la Cámara uque comprendáis la presión moral a la que estoy sometido en este momento e incluso que comprendáis el riesgo físico que puede suponer para mi las palabras que os voy a dirigir y el mantenimiento de esta enmienda...» (Diario de Sesiones del Congreso de los Diputados, Pleno, núm. 116, 21 de julio de 1978, p. 4563).

95 VARIOS: El comportament electoral a l'Estat espanyol, Edicions de la Magrana, Barcelona 1984, pp. 50-51.

${ }_{96}$ El País, 21 de octubre de 1989, p. 26.

97 Anuario El País, Ediciones El Pais, Madrid, 1989, p. 102.

${ }^{98}$ F. J. Llera Ramos: "Crisis en Euskadi en los procesos electorales de 1986", en Revista de Derecho Político, núm. 25, 1988, pp. 48 y 49.

99 El País, 31 de octubre de 1989, p. 24. 
votos emitidos en la región, mientras que los no nacionalistas habían descendido al 30,4 por 100 de los votos ${ }^{100}$.

c) A todo ello se ha sumado el aumento de las fuerzas claramente independentistas dentro del ámbito nacionalista, lo que ha provocado un progresivo escoramiento del nacionalismo hacia posiciones más radicales.

Por una parte, en el País Vasco, el partido nacionalista moderado (PNV) se escindió surgiendo un nuevo partido (Eusko Alkartasuna) que ha conseguido arrastrar, aproximadamente, a un tercio de los electores del PNV y que es claramente independentista. A esto hay que añadir el progresivo aumento, dentro del conjunto de las fuerzas nacionalistas, del voto a la coalición independentista Herri Batasuna. Ésta ha pasado de ser un grupo extraparlamentario, con el 4,3 por 100 de los votos válidos emitido en el País Vasco en el momento constituyente ${ }^{101}$, a ser una fuerza parlamentaria que obtuvo el 16,7 por 100 de los sufragios en las elecciones generales de $1989^{102}$. En sentido contrario debemos apuntar la progresiva moderación de Euskadiko Ezquerra, cuya postura en el momento constituyente ha sido ocupada por las posiciones políticas representadas por Herri Batasuna.

Por lo que respecta a Cataluña, los cambios también han sido importantes. Se ha producido una progresiva acentuación nacionalista en el discurso de Convergència i Unió. Prueba de ello es que las juventudes del partido se hayan mostrado partidarias de la independencia política de Cataluña. Además de ello, en el reciente Congreso de Esquerra Republicana, como bien ha señalado .CAVERO ${ }^{103}$, ha triunfado la línea claramente independentista. A esto hay que sumar una mayor acentuación nacionalista de los comunistas catalanes tras su unión con el grupo nacionalista de izquierda, Entesa de Cataluña.

d) Indudablemente influyó el hecho de que el derecho a la autodeterminación se estuviera planteando abiertamente en Europa, no sólo en el caso de Letonia, Estonia y Lituania, a las que han seguido otras Repúblicas soviéticas, sino también utilizándose para conseguir la unificación de las dos Alemanias ${ }^{104}$. La generalización de su defensa, e incluso su

100 Anuario El País, Ediciones El País, Madrid 1987, p. 106.

101 F. J. Llera Ramos: "Crisis en Euskadi en los procesos electorales de 1986», en Revista de Derecho Politico, núm. 25, 1988, pp. 48-49.

102 El País, 31 de octubre de 1989, p. 24.

103 I. CaVero: «La Constitución ante la autodeterminación», en Revista de la Facultad de Derecho de la Universidad Complutense, núm. 15, p. 323.

104 I. CAVERO: "La Constitución ante la autodeterminación», en RFDUC, n. ${ }^{\circ} 15,1989$, p. 325 
ejercicio, ha levantado el estigma que pesaba sobre la defensa de este derecho humano.

e) No olvidemos que cuando tuvo lugar el debate en la Comisión correspondiente del Parlamento de Cataluña, se habia elaborado en Estrasburgo la declaración sobre Europa Central y Oriental que aprobó el Consejo Europeo, integrado, como se sabe, por los jefes de Estado o Gobierno de los paises de la Comunidad Europea, en su reunión de los días 8 y 9 de diciembre de 1989. En ella se decía que los países que integran dicho Consejo desean uel fortalecimiento de la paz en Europa, donde el pueblo alemán recobrará su unidad a través de una libre autodeterminación" ${ }^{105}$. Esta declaración aprobada por el presidente González sirvió como argumentación a los diversos grupos nacionalistas en ambas Cámaras autonómicas ${ }^{106}$.

f) La necesidad de presionar al Ejecutivo central en un momento en que se iba a debatir la ampliación o no de competencias autonómicas y el procedimiento a seguir: reforma del Estatuto o transferencias de competencias por ley orgánica.

En este sentido, varios han sido los autores que se han planteado la posibilidad de que dichos acuerdos respondieran a algo más que a la simple reafirmación del derecho de autodeterminación. Un destacable ejemplo lo tenemos en el profesor DE ESTEBAN quien denunció que la aprobación de estas proposiciones no de ley era una maniobra para aumentar el ámbito competencial autonómico de Cataluña y el País Vasco, atendiendo al principio de "si se simula que se reivindica el máximo, se obtendrá al menos el mínimo" ${ }^{107}$.

En cuanto a las razones particulares que favorecieron el apoyo de los nacionalistas moderados catalanes, podemos señalar fundamentalmente:

105 Europe. Información internacional, núm. 2.355, 10 de diciembre de 1989, p. 8.

106 En concreto fue utilizada por Esquerra Republicana de Catalunya en el Parlamento de Cataluña (Diari de Sesssions, C, núm. 102, 12 de diciembre de 1989, p. 2022) y por el Partido Nacionalista Vasco, Eusko Alkartasuna y Euskadiko Ezquerra (Diario de Sesiones del Parlamento Vasco, III Legislatura, núm. 55, alea, respectivamente, pp. 39,36 y 34 ).

107 «Derecho a la autodeterminación y simulación política», en El Mundo, 18 de diciembre de 1989 , p. 8 . En igual sentido se manifiesta el profesor GonzALEZ ENCINAR, en "El Estado asimétrico", en El Independiente, 10 de enero de 1990, p. 11. También es recogido por I. Cavero, en «La Constitución ante la autodeterminación», en RFDUC, núm. 15, 1989, pp. 324-325. En otro sentido, ha sido puesto de relieve la utilización del derecho de autodeterminación como arma política por J. Corcuera Atienza, en "Pais Vasco: la autodeterminación falso problema", Cuadernos de Alzate, núm. 10, 1988, pp. 77 y ss. 
- La necesidad de impedir que se debilite el respaldo electoral sobre el que reposa el gobierno de Convergència. Quienes se presentan como la esencia y el crisol del nacionalismo y la catalanidad no pueden perder a un sector de su electorado nacionalista por no apoyar el derecho de autodeterminación.

- El profesor y diputado SOLÉ TURA arguyó otra razón más compleja. Se trataba de provocar que el PSOE, caso de perder la mayoría absoluta tras los recursos electorales en aquel momento en curso, tuviera que pactar con los nacionalistas catalanes. Para lo cual éstos necesitarian provocar que los nacionalistas vascos entraran en el juego de la autodeterminación, lo cual no seria muy difícil si se aprobaba una resolución en el Parlamento Catalán. La reproducción del debate en el País Vasco podría poner fin al gobierno de coalición que mantenian PSOE y PNV y que convertía a los nacionalistas vascos en los socios naturales, también en las Cortes Generales ${ }^{108}$.

Por su parte, en el Pais Vasco el Partido Nacionalista Vasco tenia la necesidad de, además de evitar fugas de votos nacionalistas, reforzar su identidad nacionalista demostrando que el pacto con los socialistas no le restaba un ápice de patriotismo ${ }^{109}$.

\section{ANÁLISIS JURÍDICO DE LOS ACUERDOS DE LOS PARLAMENTOS DE CATALUÑA Y EUSKADI}

Tras el estudio de los puntos anteriores no podemos concluir este trabajo sin precisar si los acuerdos adoptados son constitucionales o si, por el contrario, han violado los límites constitucionales al asumir, al menos, dos reivindicaciones políticas cuestionables constitucionalmente:

a) La defendida en común por ambas Cámaras sobre el derecho de autodeterminación del pueblo vasco y catalán que, como vimos, se trata de un derecho no reconocido constitucionalmente e incompatible, como analizamos, con varios preceptos constitucionales.

108 "Autodeterminación", en El País, 22 de diciembre de 1989, p. 18.

109 Esta razón ha sido puesta de relieve por I. CAVERO, «La Constitución ante la autodeterminación", en Revista de la Facultad de Derecho de la Universidad Complutense, núm. 15, 1989, pp. 324-325. 
b) La proclamación del Parlamento Catalán de que Cataluña es parte de una entidad nacional, denominada «Países Catalanes», que no sólo no tiene reconocimiento constitucional sino que fue rechazada implícitamente en el debate constitucional al prohibirse las federaciones entre Comunidades Autónomas. Prueba de este rechazo fue la justificación de la enmienda que introdujo el precepto ${ }^{110}$, presentada por el diputado valenciano señor Jarabo Payá, además de las propias intervenciones, en el debate del artículo 145 de la Constitución, de los nacionalistas catalanes ${ }^{111}$.

Para ello, lo primero que habrá que recordar es el valor jurídico que tienen ambos acuerdos. En ambos casos se utilizó la vía de la proposición no de ley que en el caso catalán se debatió no en el Pleno sino en una Comisión permanente ${ }^{112}$. Pues bien, dichas proposiciones no de ley, una

110 La enmienda núm. 33 (Constitución Española. Trabajos Parlamentarios, Cortes Generales, Madrid 1980, t. I, p. 144) solicitaba la incorporación del siguiente párrafo: «En ningún caso podrá constituirse la Federación de Regiones Autónomas». La enmienda fue asumida por la Ponencia con el voto favorable de UCD y AP (Boletín Oficial de las Cortes, núm. 82, 17 de abril de 1978, p. 1597) y se mantuvo, con modificaciones de estilo, hasta quedar consagrada como párrafo primero del artículo 145. La justificación que se daba en la enmienda destacaba que se presentaba "con objeto de evitar la fusión, integración o absorción de unas regiones con otras, posibilidad ésta que despierta inevitables recelos y tensiones, cuando no violento rechazo por parte de muchas provincias españolas...". Al parecer'se obviaba que, caso de que se produjera una Federación de Regiones, sería porque así lo quisieran dichas Comunidades.

111 Asi en el Pleno del Congreso, el portavoz de Minoría Catalana, señor Pujol, señaló que se habian abstenido al votar el hoy artículo 145, «aunque hubiéramos votado en contra si no estuviéramos sujetos al consenso", puesto que "en España existen hechos a veces de carácter histórico, cultural y lingüístico, otros de carácter geográfico y económico, hechos que han tejido una especial relación entre algunos futuros territorios autónomos a los que, en justicia, pensamos no debería privarse del derecho de federarse o mancomunarse dentro del marco constitucional de España", añadiendo posteriormente que uno de esos hechos es el que "lleva el nombre conocido, creo que aceptado básicamente en lo histórico, cultural y lingüístico, de Países Catalanes" (Diario de Sesiones del Congreso de los Diputados, Pleno, núm. 113, 19 de julio de 1978, pp. 4402-4403).

Por su parte el senador señor Andet Puncernau se opuso al texto del citado artículo puesto que «impide establecer una plena relación entre Cataluña Principado, el País Valenciano y las Islas Baleares", puesto que "conjuntamente componemos unas realidades históricas, con una unidad de lengua y cultura que, lógicamente, deberian llevarnos a una libre federación..." (Diario de Sesiones del Senado, Pleno, núm. 65, 3 de octubre de 1978, p. 3237).

${ }_{112}$ Al parecer la Mesa de la Cámara entendió que no tenía importancia la cuestión suscitada y al amparo del artículo 129.2 del Reglamento de la misma acordó su tramitación en una de las Comisiones permanentes que, en virtud del artículo 42 del mismo cuerpo legal, establece la competencia de éstas para examinar las propuestas no legislativas con el mismo valor que si hubiera sido tratado por el Pleno del Parlamento. 
vez aprobadas, como su propio nombre indica, carecen de la fuerza general de obligar propia de las leyes. Son, salvo que en el Reglamento parlamentario se fijen concretos efectos, simples manifestaciones de voluntad. Como SANTAOLALLA ha señalado «sirven, según los casos, para manifestar la voluntad, la aspiración o el deseo de una Cámara... A través suyo, la Cámara que los adopta no puede intentar vincular a los ciudadanos y a los restantes órganos que, en cambio, en virtud del principio de legalidad, están sujetos a lo que dispongan las leyes» ${ }^{113}$.

Independientemente de lo que hemos analizado, algunos autores se han manifestado contrarios a estos acuerdos, señalando, tal como el profesor SOLÉ TURA ha puesto de relieve, que el derecho de autodeterminación «nuestra Constitución no lo contempla y que en el momento en que se estaba elaborando se rechazó de manera explícita su inclusión» ${ }^{114}$. Sin embargo, esta visión de la polémica ha estado mal planteada. Como hemos visto los Parlamentos Vasco y Catalán no han iniciado ninguna acción para autodeterminarse. Únicamente han manifestado su deseo u opinión respecto a sus derechos como comunidad y, concretamente, respecto de su derecho de autodeterminación.

Evidentemente, como ha apuntado CAVERO, estas declaraciones carecían de efectos jurídicos ${ }^{115}$. En nuestra opinión el más certero dictamen sobre la constitucionalidad de tales declaraciones ha sido emitido por el profesor SOLOZÁBAL para quien «la reclamación del derecho de autodeterminación es lícita porque nuestra Constitución es abierta, reconoce la libertad de expresión y no tiene topes ideológicos» ${ }^{116}$.

Esta conclusión cabe mantenerla tanto de la genérica reivindicación del derecho de autodeterminación como de la manifestación del Parlamento Catalán afirmando que Cataluña es parte de una realidad no constitucional, rechazada implícitamente en el debate constitucional. El carácter abierto de nuestra Constitución permite expresar voluntades o deseos incluso anticonstitucionales. $Y$ esta garantía se predica tanto de los ciudadanos como de las instituciones o poderes públicos.

113 F. SantaOlalla LoPez: Derecho Parlamentario español, Editora Nacional, Madrid 1984, pp. 357-358.

114 "Autodeterminación", en El País, 22 de diciembre de 1989, p. 18. En igual sentido se ha manifestado el profesor DE BLAS GUERRERO en «Autodeterminación en España", en El País, 10 de enero de 1990, p. 12. 1989, p. 323.

I. CAVERo: “La Constitución ante la autodeterminación, en RFDUC, $n .^{\circ} 15$,

${ }_{116}$ Opinión recogida en la página 14 del suplemento «Los grandes temas del domingo", en El Independiente, 14 de enero de 1990. En igual sentido, más o menos, se manifiesta el profesor Cruz Villalón en el mismo dossier. 


\section{ANÁLISIS POLÍTICO DEL CONTENIDO DE LOS ACUERDOS DE LOS PARLAMENTOS DE CATALUÑA Y EUSKADI}

Puesta de relieve la constitucionalidad de los acuerdos adoptados por los Parlamentos Catalán y Vasco, hemos de analizarlos desde un punto de vista político. Y lo vamos a hacer planteando dos cuestiones:

La primera, abstracta, genérica, de dilucidar si tiene sentido plantear el derecho de autodeterminación en un Estado democrático con descentralización política. La segunda, ceñida a la realidad española, de determinar qué consecuencias políticas tienen dichos acuerdos. Fundamentalmente, como vamos a analizar, suponen incorporar la inseguridad y la desconfianza en las relaciones entre esas Comunidades y el resto del Estado y, además, dar nuevos argumentos a los grupos terroristas y sus filiales políticas.

a) ¿Tiene sentido reconocer el derecho de autodeterminación en un Estado democrático que goza de un sistema de descentralización politica?

Como ya vimos al intentar delimitar el sujeto del derecho de autodeterminación, en la práctica de las Naciones Unidas se ha confundido sujeto en abstracto del derecho con sujeto legitimado para ejercerlo. Se trata de una confusión muy extendida. Prueba de ello es que el profesor COTARELO entiende que no debe reconocerse dicho derecho por los problemas que plantea su ejercicio. Concretamente le preocupaba el reconocimiento de dicho derecho unido a la tesis de la inagotabilidad por ejercicio de cualquier derecho. Ello podría llevar al absurdo que irónicamente describe: « $i O$ se imagina alguien a una comunidad autónoma votando cada seis meses si se independiza o no? Renan, al llamar a la nación plebiscito cotidiano, hablaba en sentido figurado. No es preciso tomarse todo al pie de la letra» ${ }^{117}$.

También fueron utilizadas las consecuencias de su ejercicio para oponerse a su reivindicación desde el Partido Popular. Su portavoz en el Parlamento Vasco señaló que la autodeterminación «es la entronización de la inseguridad jurídica, no es otra cosa que la encuesta de opinión elevada

de 1989, p. 9. 
a la categoría de ley fundamental» ${ }^{118}$. Además, en el mismo debate, se insistió en ese aspecto de inseguridad poniendo de relieve que este derecho podria ser ejercido, a su vez, por alguna de las partes que compondrían un supuesto Euskadi independiente ${ }^{119}$.

EI profesor SOLOZÁBAL también rechazó el reconocimiento del derecho de autodeterminación argumentando sobre la deslegitimación para su ejercicio en España. Dicho derecho, afirmó, «puede tener sentido referido a territorios coloniales o a comunidades cuyos derechos no son en modo alguno atendidos. No es el caso de España, donde el derecho fundamental de las nacionalidades está reconocido en la Constitución y es el derecho al autogobierno» ${ }^{120}$.

En sentido contrario se manifestó el profesor GONZÁLEZ ENCINAR para quien «la autonomía de una persona, o de un millón de personas, para decidir si quieren separarse de un Estado, no es democráticamente discutible. Derecho a irse tiene todo el mundo. Quienes opinan lo contrario confunden el Estado democrático con un campo de concentración. No es discutible el si algunos se van. Ahora bien, lo que sí es perfectamente discutible, y habria, en su caso, que discutir, es el cómo se van, es decir, el qué se llevan» ${ }^{121}$.

Pero también en este caso se defendía su reconocimiento amparándose en su posible ejercicio. Parece deducirse de todo ello que sólo si es posible o legítimo ejercerlo debe ser reconocido o tiene sentido reivindicarlo. En caso contrario se mantiene la imposibilidad de su reconocimiento $y$, por tanto, la inutilidad de su reivindicación.

De manera diferente se ha manifestado un importante sector de la doctrina que ha sabido distinguir entre sujeto del derecho y posibilidad o legitimidad de su ejercicio. Esta corriente doctrinal identifica pueblo y grupo étnico diferenciado pues «lo que justifica precisamente la autodeterminación es una cultura propia y distinta de las demás» ${ }^{122}$ y la necesidad de preservarla. En este sentido, todos los grupos étnicos diferenciados dentro de cualquier Estado tienen derecho a la autodeterminación. Pero sólo es legítimo el ejercicio del derecho, además de los supuestos en que se trate de un pueblo colonial, en los casos en que un pueblo está inmerso en un Estado no democrático o en uno democrático que no respete las peculiaridades de dicha etnia. No basta, pues, con que el Estado sea democrático

118 Diario de Sesiones del Parlamento Vasco, III Legislatura, núm. 55, alea, 15 de febrero de 1990, p. 30.

119 Diario de Sesiones del Parlamento Vasco, p. 54.

120 Opinión recogida en la página 11 del suplemento «Los grandes temas del domingo", en El Independiente, 14 de enero de 1990.

121 “El Estado asimétrico», en El Independiente, 10 de enero de 1990, p. 11.

122 José A. DE OBIETA: El derecho humano de la autodeterminación de los pueblos, Tecnos, Madrid 1989, p. 62 
porque una etnia dominante, con mayoria electoral en el Estado, puede impedir que se respeten los derechos étnicos de las minorias.

Consecuentemente, en el supuesto de que exista una descentralización política, según este sector doctrinal ${ }^{123}$, no tiene sentido que se ejercite el derecho de autodeterminación pues sólo puede pretender la secesión ${ }^{124}$. Y la secesión es una solución extrema solamente aplicable en supuestos de flagrante violación de los derechos étnicos.

Con esta argumentación, sin embargo, no parece que tenga sentido el reconocimiento de un derecho a un pueblo que no está legitimado para ejercerlo. En este sentido, Cataluña, Pais Vasco y Galicia, prototipos de identidades étnicas, no necesitarían que se reconociera su derecho a la autodeterminación pues carecen de legitimación para ejercer dicho derecho dado que disfrutan de un amplio ámbito de autogobierno.

Pero, en nuestra opinión, desde una postura democrática, hemos de ir más allá. Hemos de inclinarnos por la tesis defendida por el profesor HÉRAUD: del derecho de autodeterminación ha de disponer cualquier colectivo humano que tenga conciencia de unidad y de diferenciación respecto de otros colectivos, sea cual sea su amplitud y sus circunstancias políticas. Aunque en un Estado democrático descentralizado no existan razones objetivas para entender el deseo de autodeterminación, hay que respetar la voluntad de las personas y de los grupos en que se integra.

Podremos pensar que no tiene sentido objetivamente, pero no podemos olvidar que lo tiene para los interesados. Nos encontramos fundamentalmente ante un problema de psicologia social ${ }^{125}$. Posiblemente, si un pueblo, partiendo de una situación política descentralizada o federal, ejerce

${ }^{123}$ Por todos, José A. de OBIETA, op. cit., pp. 155-178. Para este autor, sería además jurídicamente discutible el ejercicio del derecho de autodeterminación si la etnia goza de un sistema de autonomía, en los supuestos que tenga por finalidad secesionarse una minoría nacional para integrarse en un Estado de su misma etnia o secesionarse partes de un pueblo enteramente dividido entre varios Estados para obtener su reunificación. También para los supuestos en que sea inviable la convivencia de diversos pueblos dentro de un Estado (pp. 179-205).

${ }_{124}$ Otros sectores doctrinales son más estrictos a la hora de legitimar la secesión de un Estado. Para Buchheit son necesarios tres factores: a) La presencia del elemento objetivo y subjetivo que delimita que se trata de un pueblo dicha comunidad; b) la capacidad de ser independiente; c) que no suponga un factor distorsionador, bien sobre el antiguo Estado y sobre terceros, bien sobre el orden internacional (Lee C. BuchHEIT: Secession. The Legitimacy of Self-Determination, Yale University Press, New Haven-London 1978, pp. 228-231).

${ }_{125}$ La importancia de las «realidades psico-politicas de una situación dada» han sido puestas de relieve por Buchheit al recordarnos que los colonos ingleses en América, a pesar de pertenecer a una misma nación, se sentían oprimidos por sus compatriotas de la metrópoli y optaron por secesionarse (Lee C. BUCHHEIT: op. cit. p. 11). 
hoy el derecho de autodeterminación, tendrá que articularse, más tarde o más temprano, en una fórmula política que, en la práctica, tendrá la misma configuración que la actual. Pero lo que a un pueblo le provoca el sentimiento de opresión es el hecho de que no se le dé la oportunidad de elegir libremente entre todas las alternativas politicas que, en abstracto, son posibles.

Consecuentemente, creemos que en los casos de Estados democráticos descentralizados, el mero reconocimiento del derecho de autodeterminación podría zanjar el problema. Con ello, los pueblos implicados tendrían la certeza de que, aunque no lo ejerzan, nada les impide, juridicamente, adoptar una solución diferente. Evidentemente, se sentirán psicológicamente más libres aunque, posiblemente, la realidad les impida alcanzar otra forma política de organización.

Hay que recordar que el concepto de soberania del Estado ha perdido sentido dada la creciente interdependencia de los Estados. Sin embargo, los ciudadanos de un Estado nos sentimos libres, aunque no podamos realmente hacer aquello que como Comunidad quisiéramos, porque sabemos que, al menos juridicamente, es posible adoptar cualquier decisión.

Defendida nuestra postura favorable a que, incluso en un Estado democrático descentralizado, se deba reconocer, y por tanto reivindicar, el derecho de autodeterminación de un determinado pueblo, pasemos a ver las dos graves consecuencias políticas que pueden derivarse de las Resoluciones de los Parlamentos Catalán y Vasco.

\section{b) La sombra de la desconfianza política}

Las resoluciones aprobadas en Cataluña y el País Vasco, como hemos visto, son una reivindicación teórica del derecho de autodeterminación. Nada se dice de exigir su incorporación al ordenamiento jurídico español o de plantear su ejercicio. En consecuencia, introduce un elemento de inseguridad y desconfianza en las relaciones políticas del País Vasco y Cataluña con el resto del Estado ${ }^{126}$. Constantemente, el resto de los españoles

${ }^{126}$ Esto fue puesto de relieve por el portavoz del Centro Democrático y Social en el Parlamento Vasco cuando denunció que los grupos proponentes trataban de proclamar «más que el ejercicio de una autodeterminación concreta, el derecho formal a poder ejercer su derecho de autodeterminación en el futuro, de una manera que, aunque hoy no se especifica, se podrá en su dia concretar (...) ¿Acaso no es irresponsable, y además incoherente, reservarse desde una institución del Estado, como es el Parlamento Vasco, el derecho a poner en cuestión el propio Estado?" 
y los gobernantes de las demás Comunidades Autónomas y, especialmente, del Estado van a mantener unas relaciones políticas basadas en el recelo hacia dichas Comunidades que en cualquier momento pueden dar un nuevo paso en el camino a su libre determinación ${ }^{127}$. En este sentido, no parece que los acuerdos aprobados sean la mejor vía para conseguir el imprescindible espíritu de lealtad y de fidelidad que debe presidir las relaciones de los pueblos de todo Estado ${ }^{128}$.

Para evitar esta sensación de inseguridad, el portavoz de Euskadiko Ezquerra defendió que «la palabra autodeterminación encierra un doble valor: el de la capacidad de un pueblo para decidir su futuro, y también el valor de respetar y acatar las decisiones, todas y cada una de las decisiones que ese mismo pueblo vaya adoptando a lo largo de la historia ${ }^{129}$. Sin embargo, el apoyo dado a la proposición no de ley autodeterminista sin duda ha quitado fuerza y garantía a estas manifestaciones.

\section{c) Un grave riesgo político}

Por otra parte, cabe deducir una grave consecuencia de toda esta polémica. Aunque por algunos políticos nacionalistas se defendió que la reivindicación del derecho de autodeterminación realizada por los Parlamentos Catalán y Vasco supuso arrebatar una bandera a los grupos nacionalistas radicales o violentos ${ }^{130}$, el problema que puede surgir puede ser mayor que el que se intentó evitar.

(Diario de Sesiones del Parlamento Vasco, III Legislatura, núm. 55 alea, 15 de febrero de 1990, p. 51). En el mismo sentido el portavoz de los socialistas vascos se preguntó: “¿Qué sentido tiene exigir a las inmediatas el reconocimiento de un derecho para dejar indefinidamente suspendido su ejercicio? ¿Se trata sólo de obtener una satisfacción moral? (...) ¿O se trata más bien de dejar suspendido el ejercicio de ese derecho como una amenazante espada de Damocles, para elevar el conflicto y la tensión a la categoría estratégica del nacionalismo?" (Diario de Sesiones del Parlamento Vasco, p. 55).

${ }^{127}$ En este sentido, el presidente del Gobierno puso de relieve a los medios de comunicación que las propuestas autodeterministas “le han generado una profunda desconfianza hacia sus autores que llevará mucho tiempo superar». Por ello «a partir de ahora lo pensará dos veces antes de dar un paso, por milimétrico que sea, dirigido a la descentralización del Estado, ya que deberá pensar no sólo en la letra de las normas, sino en las intenciones de quienes las reclaman" (EI País, 7 de enero de 1990, p. 13).

${ }^{128}$ Así lo puso de relieve el portavoz del PSE-PSOE cuando afirmó en la Cámara vasca que "cuando se quiere, como en España, consolidar un único Estado que además de un polo central de poder tenga otros polos descentralizados, es absolutamente necesario que exista cooperación y lealtad entre todos ellos» (Diario de Sesiones del Parlamento Vasco, III Legislatura, núm. 55, alea, 15 de febrero de 1990, p. 51).

129 Diario de Sesiones del Parlamento Vasco, p. 31.

130 El señor Aulestia, portavoz de Euskadiko Ezquerra en la Asamblea vasca, 
Con la aprobación de las proposiciones no de ley, las propuestas que hasta hace poco eran defendidas por dichos grupos extremistas o terroristas, han sido asumidas, al menos formalmente, por la mayoría de la sociedad vasca y catalana a través de sus representantes ${ }^{131}$.

Consiguientemente, era lógico pensar que los nacionalistas radicales con representación parlamentaria acto seguido propondrían la iniciativa de reforma constitucional desde las Cámaras regionales, con el fin de que se reconociera en el ordenamiento español el derecho de autodeterminación de los pueblos de España. ¿Cómo iban a negarse a apoyar dicha propuesta los mismos grupos que han defendido una proposición no de ley en la que se reivindicaba dicho derecho?

$Y$ asi ha ocurrido en el País Vasco *. Sin embargo, las fuerzas políticas vascas han podido evitar manifestarse debido a un motivo técnico-

defendió que la proposición no de ley se presentó «para desarmar físicamente y para desarmar politicamente a los violentos» (Diario de Sesiones..., p. 32). El señor Porres, de Eusko Alkartasuna, refiriéndose a Herri Batasuna dijo que "se han quedado solos, y el acuerdo mayoritario de hoy les va a dejar más solos y aislados, en un callejón sin salida» (Diario de Sesiones..., p. 38). Por su parte, el representante del Partido Nacionalista Vasco mantuvo que en un país como el nuestro en el que una organización violenta, que dice operar en nombre del pueblo vasco, encabeza su reivindicación política con el principio de la autodeterminación; en el que este principio es utilizado como bandera de agitación en un patente empeño de legitimar una alternativa revolucionaria y antidemocrática con la invocación de este derecho, resulta urgente canalizar las preocupaciones de nuestra sociedad alli donde deben ser expuestas y tratadas democrática y civilizadamente, dentro de unas reglas de juego que sustraigan cualquier aspiración legítima del ámbito de la coacción, de la manipulación, del contrabando ideológico, de la bomba y de la pistola, de la elevación del conflicto permanente a estrategia política premeditada" (Diario de Sesiones..., p. 40).

${ }_{131}$ El portavoz del Partido Socialista de Euskadi, señor Buesa, lo expuso contundentemente: "Hace unos meses la autodeterminación era una bandera que ellos solos (se refiere a los representantes de Herri Batasuna) agitaban: trece sobre setenta y cinco en términos de aritmética parlamentaria, como alguno ha recordado gráficamente. Pero hoy esa bandera la asumen 39 parlamentarios más, y, por mucho que quieran ustedes matizarlo, ¿cómo pueden caer en la ingenuidad de pensar que trayendo al Parlamento este tema lo sacarán de la calle? No dudo de la firmeza de sus posiciones frente a la violencia (...), pero ¿creen ustedes de verdad que el apoyo que ustedes prestan a la autodeterminación no será recogido por Herri Batasuna para volver luego a la calle, a seguir sosteniendo con más fuerza la causa de ETA?» (Diario de Sesiones del Parlamento Vasco, III Legislatura, núm. 55, alea, 15 de febrero de 1990, p. 55).

* Estando en fase de publicación este artículo, se ha presentado una propuesta de resolución por Esquerra Republicana de Catalunya ante el Parlamento Catalán, en la que se afirmaba que el derecho a la autodeterminación incluye el derechó democrático a la independencia política. Dicha propuesta de resolución no prosperó y obligó al Presidente Pujol a declararse ante el Parlamento de Cataluña, contrario a la independencia de esta región. 
jurídico. En efecto, la iniciativa para activar la reforma constitucional fue propuesta a través de la iniciativa legislativa popular ante el Parlamento Vasco y no, como hubiera sido lógico, por el grupo parlamentario de Herri Batasana. Gracias a esto, la Mesa del Parlamento pudo declarar la inadmisión de la citada iniciativa pues la misma es una iniciativa que recae sobre otra iniciativa legislativa que ha de ejercer la Cámara. *

$\mathrm{Si}$, se hubiese conseguido el acuerdo de las Cámaras autonómicas, la propuesta de reforma constitucional difícilmente hubiera sido aceptada por las Cortes Generales. En este caso, y habiendo quedado constatado que la voluntad mayoritaria de los pueblos vascos y catalán no es atendida por el resto de los pueblos que componen España, ¿no tendrán más argumentos los violentos para legitimar la lucha armada como única vía para conseguir el reconocimiento de los derechos nacionales de los pueblos vasco y catalán? En definitiva, esa es precisamente la tesis de los grupos terroristas ${ }^{132}$ : por la vía pacífica, de las instituciones, nunca se podrán llevar a la práctica las aspiraciones que, ahora sí, pueden decir que son mayoritarias en ambos pueblos; consecuentemente, el único camino que resta es la lucha armada.

Sean cuales sean las consecuencias futuras de las resoluciones de los Parlamentos Vasco y Catalán lo que sí que parece evidente es que parece difícil que se pueda consolidar un Estado de las características del español si no es bajo la fórmula de la confianza recíproca Administración central-Administración autonómica y de la fidelidad de las Comunidades Autónomas respecto del resto del Estado. Por ello, urge adoptar una postura comprometida que haga que desaparezcan las ambigüedades en las relaciones entre todos los pueblos que hoy componen España.

* Boletín Oficial del Parlamento Vasco, IV Legislatura, núm. A-II-1 (b) alea, de 21 de enero de 1992.

${ }_{132}$ Efectivamente, el portavoz de Herri Batasuna afirmó en el debate: «Consigan efectivamente, inicien efectivamente negociaciones con el Estado español para el reconocimiento del derecho de autodeterminación. Háganlo; pero, si no son capaces, si no tienen voluntad política, como se deduce, como se colige del contenido de la autoenmienda, no tienen ningún derecho a protestar porque a través de otras vías no institucionales se pueda precisamente buscar la solución a este problema. En esto consiste precisamente la negociación entre ETA y el Estado» (Diario de Sesiones del Parlamento Vasco, III Legislatura, núm. 55, alea, 15 de febrero de 1990, p. 27). 